LUIZ GUILHERME VEIGA VALENTE

\title{
DIREITO, ARTE E INDÚSTRIA: \\ O problema da divisão da propriedade intelectual na Economia Criativa
}

Tese de Doutorado

Orientador: Prof. Doutor Carlos Pagano Botana Portugal Gouvêa

Universidade de São Paulo

Faculdade de Direito

São Paulo

2019 
DIREITO, ARTE E INDÚSTRIA:

\section{O problema da divisão da propriedade intelectual na Economia Criativa}

Tese apresentada à Banca Examinadora do Programa de Pós-Graduação em Direito, da Faculdade de Direito da Universidade de São Paulo, como exigência parcial para obtenção do título de Doutor em Direito, na área de concentração Direito Comercial, sob a orientação do Prof. Doutor Carlos Pagano Botana Portugal Gouvêa.

São Paulo 


\section{Serviço de Processos Técnicos da Biblioteca da}

Faculdade de Direito da Universidade de São Paulo

Valente, Luiz Guilherme Veiga

Direito, arte e indústria: o problema da divisão da propriedade intelectual na Economia Criativa / Luiz Guilherme Veiga Valente. - São Paulo, 2019. 375 p. ; $30 \mathrm{~cm}$.

Tese (Doutorado) - Programa de Pós-Graduação em Direito, Faculdade de Direito, Universidade de São Paulo, São Paulo, 2019.

Orientador: Carlos Pagano Botana Portugal Gouvêa.

1. Propriedade intelectual. 2. Direito autoral. 3. Propriedade industrial. 4. Economia da cultura. I. Gouvêa, Carlos Pagano Botana Portugal, orient. II. Título. 


\section{LUIZ GUILHERME VEIGA VALENTE}

\section{DIREITO, ARTE E INDÚSTRIA:}

\section{O problema da divisão da propriedade intelectual na Economia Criativa}

Tese apresentada à Banca Examinadora do Programa de Pós-Graduação em Direito, da Faculdade de Direito da Universidade de São Paulo, como exigência parcial para obtenção do título de Doutor em Direito, na área de concentração Direito Comercial, sob a orientação do Prof. Doutor Carlos Pagano Botana Portugal Gouvêa.

São Paulo, de de 2019 .

Nome:

Nome:

Nome:

Nome:

Nome: 
"O velho emergiu, refrescado, sorridente, salpicando confiança. - É isso. Anos atrás, você sabe, a arte era um subproduto da religião.

- A arte? - perguntei com a taça no ar.

- A arte. A música, a pintura, os livros. Na Idade Média, tudo estava a serviço da Igreja. - Zombou de minha admiração, sacudiu a cabeça para confirmar o que dissera. - Era assim. Agora não é mais, mas estamos indo por aí, a arte está a serviço da propaganda. Música para o rádio; desenhos, pinturas para os anúncios, os cartazes; literatura para os textos, os booklets. Que tal? Em Paris e Nova York fizeram propaganda com versos de poetas de primeira linha. Então, não é só o caso de conseguir ganhar dinheiro. Há muitas outras coisas, é uma área complicada". 


\section{AgRAdecimentos}

Agradeço primeiramente a meu irmão, Maurício, que me ensinou a ler e a escrever, e a meus pais, André e Celina, por todo o amor e suporte incondicionais nesta empreitada acadêmica.

Sou também extremamente grato a meu orientador, Prof. Carlos Portugal Gouvêa, pela imensa paciência, confiança e atenção ao longo desta jornada.

Agradeço, da mesma forma, à Prof. a Severine Dusollier, do Instituto de Ciências Políticas de Paris (Sciences Po); ao Prof. Lionel Bently, da Universidade de Cambridge; aos Profs. Gaetano Dimitta, Florian Koempel e Apostolos Chronopoulos, do Centro de Estudos em Direito Comercial da Queen Mary University of London; e aos Profs. José Reinaldo Lima Lopes e Juliana Krueger Pela, da Faculdade de Direito da Universidade de São Paulo, pelas valiosas sugestões e comentários.

Expresso igual gratidão a Rodrigo Valverde, a quem, muito mais do que um chefe, considerarei sempre como um amigo e um irmão.

Não menos importantes, agradeço aos demais familiares e amigos, por estarem ao meu lado sempre que preciso.

Sou grato também a Lena e Luciana, sem a ajuda de quem eu não teria chegado até aqui.

Por fim, agradeço à Faculdade de Direito da Universidade de São Paulo, que me permitiu realizar esta pesquisa, e, sobretudo, à população paulista, que financia a Universidade por meio de imposto regressivo, especialmente oneroso aos mais pobres. 


\section{RESUMO}

VALENTE, Luiz Guilherme Veiga. Direito, arte e indústria: O problema da divisão da propriedade intelectual na Economia Criativa. 2019. 375 p. Tese (Doutorado) Universidade de São Paulo, São Paulo.

Os regimes da propriedade intelectual enfrentam problemas de adaptação no cenário contemporâneo. O surgimento da Economia Criativa, de um lado, e a evolução do próprio conceito de arte, de outro, provocaram uma aproximação entre artigos industriais e obras artísticas, passando estas a serem produzidas também dentro de uma lógica comercial. Essas mudanças não foram acompanhadas pelo Direito, resultando em institutos jurídicos que hoje não se aplicam apropriadamente, ao tutelarem excessivamente bens considerados como artísticos (tais quais esculturas, desenhos, fotografias e filmes), ao mesmo tempo em que dispensam tratamento menos restritivo para produtos semelhantes, de setores econômicos em ascensão, como artigos de design. Este trabalho confirma a hipótese de que tal descompasso se deve à manutenção da divisão histórica das categorias da propriedade intelectual (a propriedade industrial e os direitos autorais), engessando a visão clássica da separação entre arte e indústria. Como solução, propomos uma série de diretrizes para orientar eventuais reformas legislativas, como também a doutrina e a jurisprudência, visando a reduzir a defasagem tanto entre os dois regimes jurídicos, quanto entre sua fundamentação original e a realidade atual de sua tutela.

Palavras-chave: 1. Propriedade intelectual. 2. Direito autoral. 3. Propriedade industrial. 4. Economia da cultura. 


\begin{abstract}
VALENTE, Luiz Guilherme Veiga. Law, art and industry: The problems caused by the divide of intellectual property in the Creative Economy landscape. 2019. 375 p. Doctorate Thesis - University of São Paulo, São Paulo.

Intellectual property legal regimes in Brazil struggle to adapt to the current society. The emergence of the Creative Economy as well as the evolution of the concept of art have brought together industrial items to artistic works. Such changes have deep implications that are not reflected in Law. Legal regimes associated with intangible goods do not apply properly nowadays, as they rigorously protect objects considered as artistic (such as sculptures, drawings, photographs and films), but do not provide the same treatment for similar items provided by new economic sectors, like design products. This research argues that such discrepancy is due to the maintenance of the historical division between the categories of intellectual property, particularly, author's rights and industrial property, deepening the classic distinction between industry and art. As a solution, we advance a series of guidelines for reformers, legislators, scholars and judges, in order to reduce the gap between the two legal regimes, and the mismatch between their original rationale and the reality they currently protect.
\end{abstract}

Keywords: 1. Intellectual property. 2. Copyright. 3. Industrial property. 4. Culture economy. 


\section{RÉSUMÉ}

VALENTE, Luiz Guilherme Veiga. Droit, art et industrie: Les problèmes provoquées par la divison de la propriété intellectuelle dans l'Économie Créative. 2019. 375 p. Thèse Doctorale - Université de São Paulo, São Paulo.

Les régimes juridiques de propriété intellectuelle ont du mal à s'adapter dans le contexte contemporain. L'émergence de la Économie Créative, d'une part, et l'évolution du concept d'art lui-même, d'autre part, ont conduit à un rapprochement entre produits industriels et œuvres artistiques, ces dernières étant aujourd'hui également produits dans une logique commerciale. Ces modifications n'ayant pas été prises en compte par la loi, les régimes juridiques relatifs aux créations immatérielles ne disposent pas d'une application adéquate de nos jours. Par conséquent, le Droit protège de façon excessive les actifs considérés comme artistiques (tels que les sculptures, les dessins, les photographies et les films), tandis que des produits similaires sur lesquels se sont basés des secteurs économiques émergents, comme le design, bénéficient d'un encadrement plus souple. Cette étude confirme l'hypothèse selon laquelle cette divergence est due au maintien de la division historique des catégories de propriété intellectuelle (notamment les droits d'auteur et la propriété industrielle), renforçant ainsi la séparation classique entre industrie et art. En guise de solution, nous proposons une série de lignes directrices pour mener des réformes législatives éventuelles, la doctrine juridique et la jurisprudence, afin de réduire l'écart entre les deux régimes juridiques, ainsi que le déséquilibre entre leur raison d'être d'origine et la réalité actuelle de leur protection.

Mots-clés: 1. Propriété intellectuelle. 2. Droit d'auteur. 3. Propriété industrielle. 4. Économie culturelle. 


\section{SUMÁRIO}

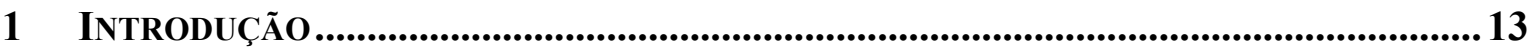

2 AS FUNÇõES SOCIOECONÔMICAS DA ARTE....................................................................19

2.1 Da Antiguidade ao século XIX ……………………………………………...... 19

2.2 A divisão entre arte e artesanato ....................................................................... 27

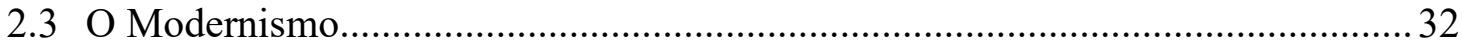

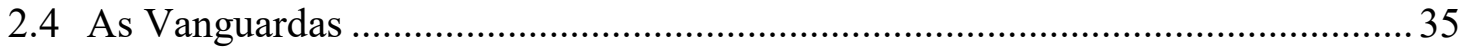

2.5 A Arte Contemporânea.................................................................................. 40

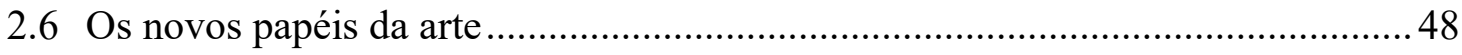

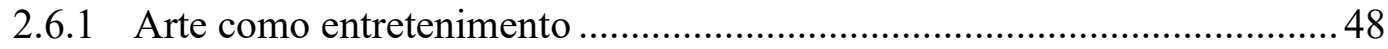

2.6.2 Arte como publicidade......................................................................... 50

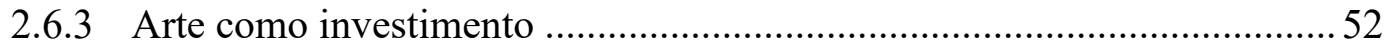

2.7 O artista-empresário e a empresa-artística …………………………………........5

2.8 Indústria Cultural e Economia Criativa.................................................................. 58

3 A EVOLUÇÃO DA PROPRIEDADE INTELECTUAL: DOUTRINA AUTORALISTA..................62

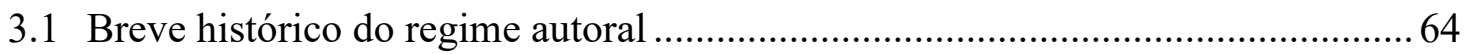

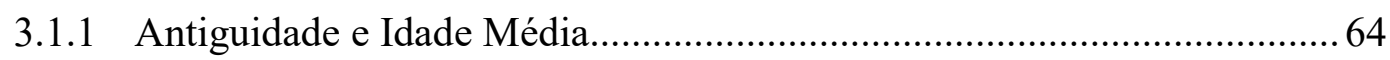

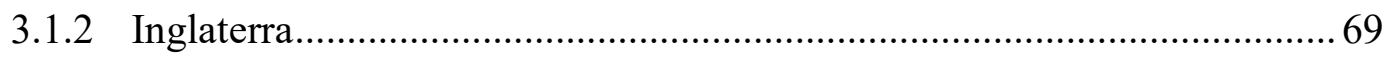

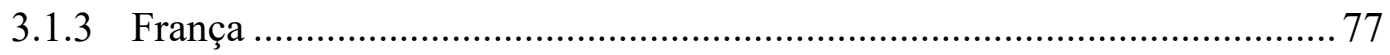

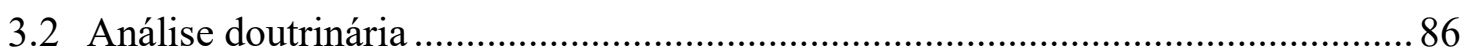

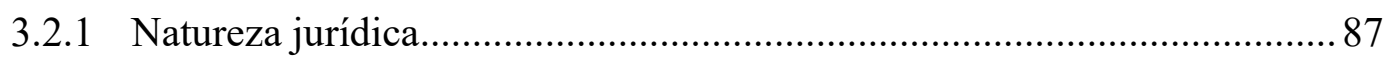

3.2.2 Diferenças em relação à propriedade industrial ........................................ 96

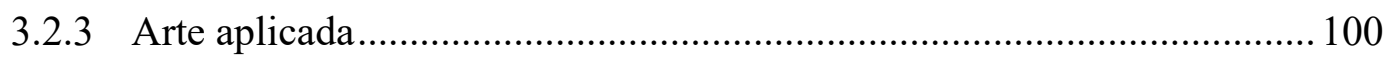

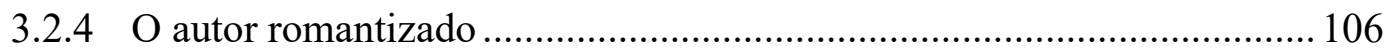

3.2.5 A questão econômica........................................................................... 110

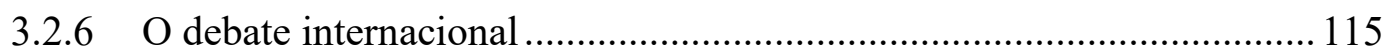

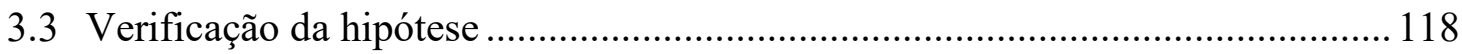

4 A EVOLUÇão dA PROPRIEDADE INTELECTUAL: DEBATES LEGISLATIVOS ................. 123

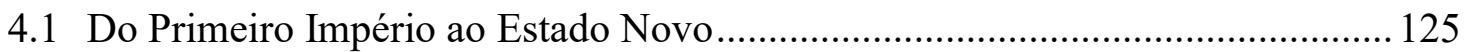

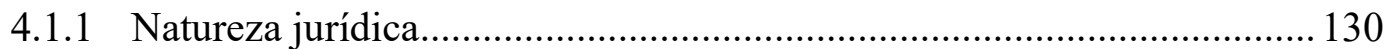

4.1.2 Diferenças em relação à propriedade industrial ....................................... 135

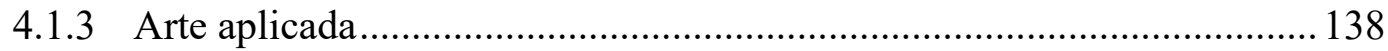




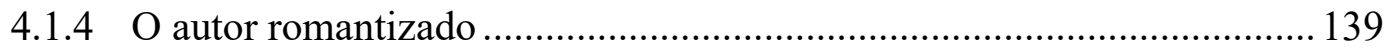

4.1.5 A questão econômica.......................................................................... 142

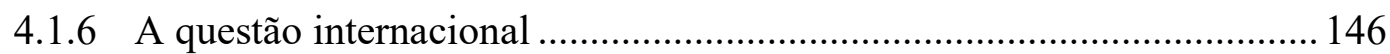

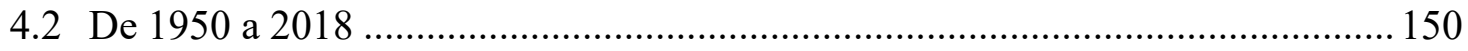

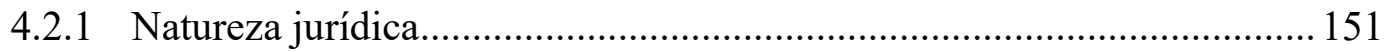

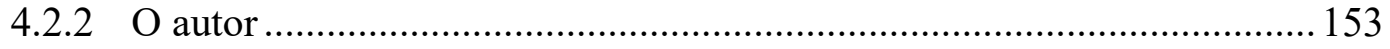

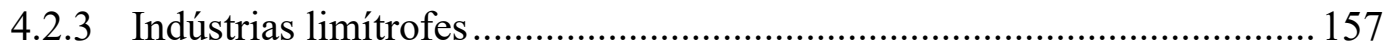

4.2.4 A questão econômica............................................................................ 162

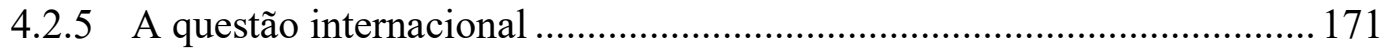

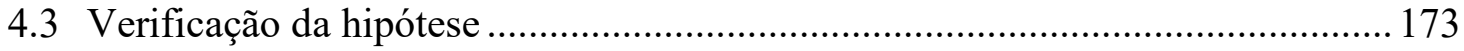

5 OS PROBLEMAS DA ATUAL DIVISÃO DA PROPRIEDADE INTELECTUAL........................ 178

5.1 Direitos autorais $v s$. propriedade industrial ................................................... 179

5.1.1 O objeto de tutela dos direitos autorais .............................................. 180

5.1.2 O objeto de tutela da propriedade industrial.......................................... 188

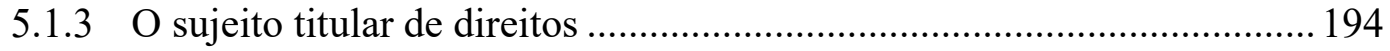

5.1.4 A justificativa econômica ..................................................................... 201

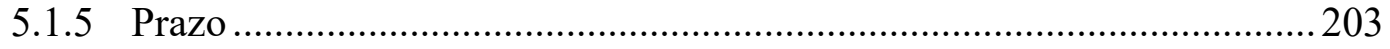

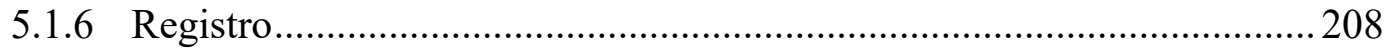

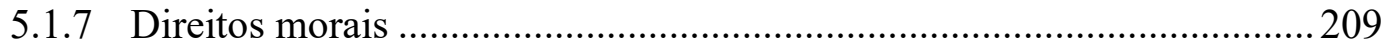

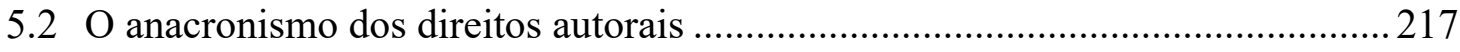

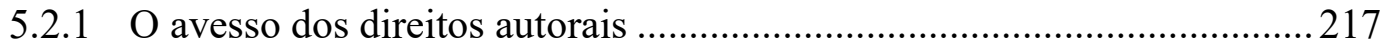

5.2.2 Direitos autorais como direitos de personalidade ................................. 222

5.2.3 Direitos autorais como direitos humanos ............................................. 229

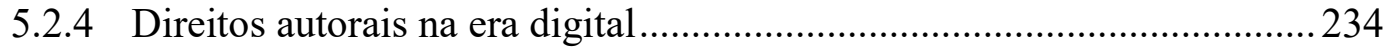

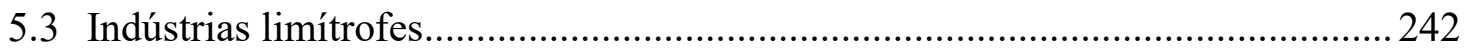

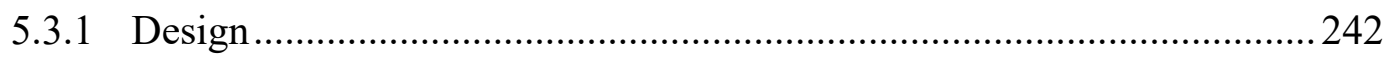

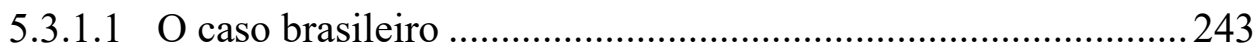

5.3.1.2 Caso inglês: noções artísticas e proteção industrial .................. 247

5.3.1.3 Caso inglês: O que é arte? O pandemônio judicial....................259

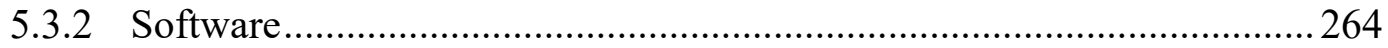

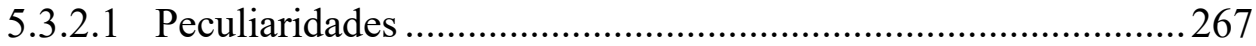

5.3.2.2 Tutela brasileira: um regime sui generis.............................. 270

6 PoSSÍVEIS SOLUÇÕES ................................................................................................... 276

6.1 Modelos alternativos à propriedade intelectual................................................2 277 


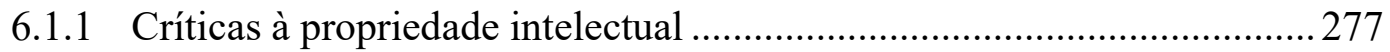

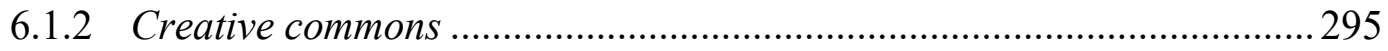

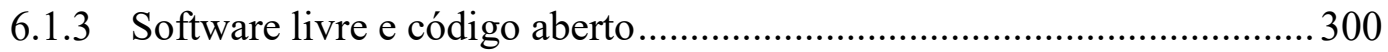

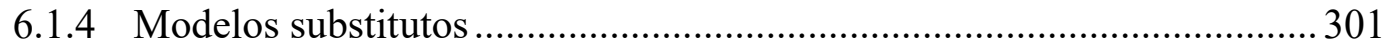

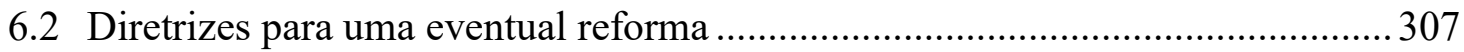

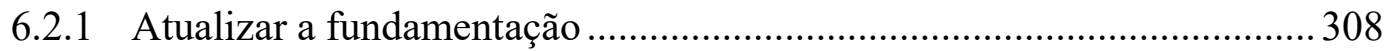

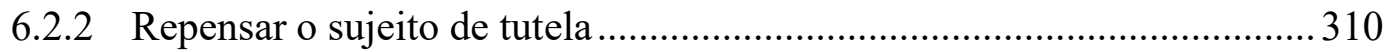

6.2.3 Repensar classificação como direitos humanos e de personalidade........ 312

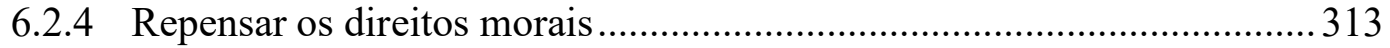

6.2.5 O objeto de tutela: mais ou menos categorias?.................................... 315

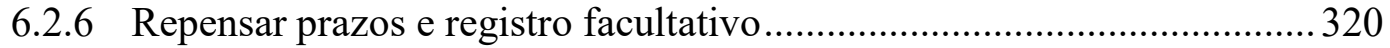

6.2.7 Consideração dos efeitos econômicos e sociais .......................................324

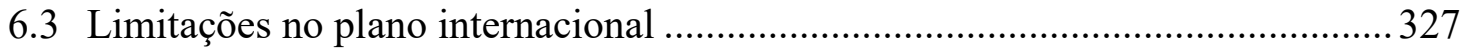

6.3.1 Ausência de limitações à reconsideração do sujeito da tutela .................. 329

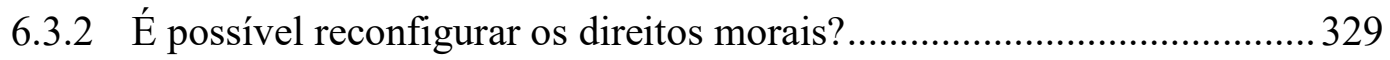

6.3.3 Limitações à reorganização das categorias..............................................330

6.3.4 É possível repensar os prazos e facultatividade do registro?................... 334

6.3.5 Futuras abordagens: uma reforma mais ampla ...................................... 335

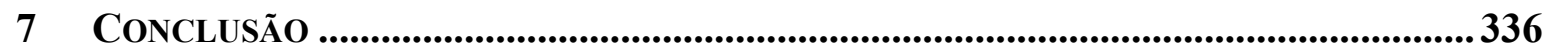

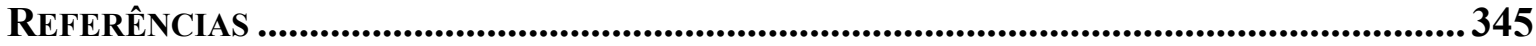




\section{LISTA DE QUADROS}

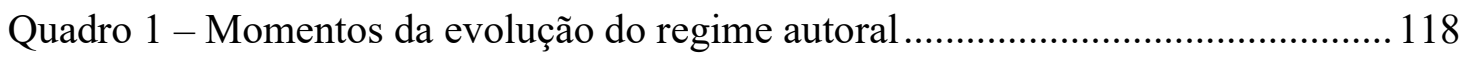

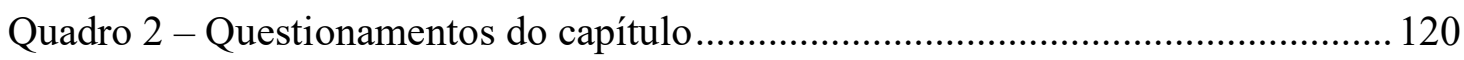





\section{INTRODUÇÃo}

“[...] ganhar dinheiro é arte, trabalhar é arte, e bons negócios são a forma suprema de arte". Dita originalmente em 1975, essa frase tornou-se um dos maiores clichês de Andy Warhol (2007, p. 92), o que não a impede de traduzir com exatidão o rumo que tomou a arte a partir da segunda metade do século XX e que predomina até os dias atuais. Isso não significa, porém, que a lógica mercadológica tenha sempre imperado no cenário artístico.

A arte tem apresentado uma série de papéis socioeconômicos distintos ao longo da História, que revelam diferentes noções de autor e obra, bem como da forma como ambos se relacionam - tanto do ponto de vista da criação como de sua comercialização. Entre o Renascimento e a primeira metade do século XX predominou a ideia da profissão artística como algo sacramental, uma expressão da individualidade humana. Em razão disso, a arte passou a ser vista como algo distinto de funções utilitárias, como o artesanato. Dessa maneira, sendo o mercado visto como atividade menos "elevada", se censuraria (moral e, por vezes, legalmente) o artista que se imiscuísse com a venda de suas obras.

Foi nesse período que os regimes contemporâneos da propriedade intelectual surgiram. Tendo os privilégios concedidos pelo Estado como forma embrionária, desenvolveram-se entre o final do século XVIII e a primeira metade do século XIX como reconhecimento de um direito natural, junto às demais prerrogativas do cidadão difundidas pelo Iluminismo. Em paralelo à separação entre arte e indústria, estabeleceu-se uma divisão do instituto em duas grandes categorias: a propriedade industrial, direcionada à proteção das criações utilitárias, de modo mais próximo do sistema dos privilégios; e os direitos autorais, voltados às obras estéticas, "criações do espírito", sobre os quais se atribuiu um caráter de tutela de personalidade. ${ }^{1}$

Entretanto, se o cenário artístico modificou-se no decorrer do século XX, com a reaproximação da arte e do mercado na emergência da chamada Economia Criativa, a estrutura bipolar da propriedade intelectual - para usar a terminologia de Reichman (1994)

\footnotetext{
Ao longo deste trabalho, falaremos em história da arte e da propriedade intelectual de forma genérica. Note-se, todavia, que o nosso recorte se restringe à perspectiva ocidental, deixando de fora uma série de outros países. Por mais que se exclua, assim, uma vasta e interessante parte da história humana (tanto artística como dos direitos intelectuais), a concisão metodológica e a falta de elo com o caso brasileiro exigem essa demarcação geográfica.
} 
- manteve-se ainda mais firme, por meio da expansão do regime autoralista, afastando-se do seu antípoda: as marcas, as patentes e os desenhos industriais.

Tais setores limítrofes (como o design, a moda, as bases de dados e, mais tarde, os softwares) acabam por apresentar problemas para a aplicação da configuração clássica da propriedade intelectual. Doutrina, legislador e jurisprudência por vezes se ocuparam dos desafios trazidos por essas novas indústrias. Não obstante, costumam focar sobre cada um desses domínios separadamente, não identificando o problema na incompatibilidade entre a macrodivisão do instituto jurídico e a nova realidade econômica e artística. ${ }^{2}$ Dessa forma, as soluções que trazem acabam por ser pontuais e imediatistas, e, portanto, incapazes de endereçar devidamente os pontos que visam a resolver.

Este trabalho propõe outra abordagem. Nossa hipótese é de que os conflitos de adaptação da propriedade intelectual à Economia Criativa resultam do fato de sua estrutura bipolar basear-se num modelo de produção artística ultrapassado, não tendo a fundamentação contemporânea dos direitos autorais e da propriedade industrial acompanhado as transformações sociais e econômicas dos mercados artísticos.

Para tanto, dividiremos nossa análise em seis partes.

No Capítulo 2, exporemos como a arte assumiu diferentes funções ao longo da História. Veremos, portanto, como passou de um meio de consolidação da nobreza e de propaganda religiosa, na Antiguidade e na Idade Média, para um veículo de propaganda dos Estados e, posteriormente, da burguesia iluminista. De igual maneira, explicaremos a evolução da sua forma de financiamento: do mecenato, no início da Era Moderna, para o desenvolvimento dos mercados consolidados de obras artísticas, entre os séculos XVIII e XX. Nesse sentido, analisaremos sua separação em relação ao artesanato, no Renascimento, focando, progressivamente, numa perspectiva mais individualista do autor e da obra (esta como expressão da personalidade daquele) e de afastamento da práxis cotidiana. Em seguida, investigaremos como, no final do século XIX, esse cenário seria paulatinamente criticado: primeiramente, pela reação do Modernismo à ascensão das

2 A exceção é Reichman (1994 e 1995), que estudou o problema de forma mais holística. No entanto, como explicaremos ao longo deste trabalho, nos distanciamos de sua visão na medida em que este vê mais semelhança entre os regimes criados para atender as indústrias limítrofes do que entre estes e os institutos localizados nos polos do espectro da propriedade intelectual (isto é, os direitos autorais e a propriedade industrial). Na mesma linha, Reichman não enxerga uma discrepância entre a fundamentação do regime autoralista e a realidade que visa a tutelar hoje, não vislumbrando uma aproximação deste em relação às marcas e patentes. Por fim, seu enfoque recai, em grande parte, sobre categorias que, para nós, não são o cerne do problema, como cultivares e topografias de circuitos integrados. 
formas de reprodução em massa; e, posteriormente, pelas Vanguardas, rompendo radicalmente com a concepção autônoma de arte. Nesse contexto, observaremos o surgimento de correntes tentando uma reaproximação de arte e indústria, como o Arts \& Crafts, a Art Nouveau e, no começo do século XX, a Escola Bauhaus. Por sua vez, estudaremos de que maneira, por volta dos anos 1950, movimentos como o Popismo introduziriam a aceitação do aproveitamento comercial da obra pelo próprio artista. Analisaremos, então, os papéis mercadológicos que a arte assume nesse novo cenário, de entretenimento, publicidade e investimento. Nessa linha, veremos em que consiste a Economia Criativa, resultante das transformações percebidas no século XX.

Nos Capítulos 3 e 4, traremos uma breve visão geral da origem e evolução dos regimes jurídicos relativos às criações artísticas, literárias e científicas. Nosso objetivo é identificar os contextos, os interesses e os argumentos por trás dos mecanismos de proteção dessas obras, a fim de verificar se existe um paralelo histórico entre as normas brasileiras e as mudanças na produção artística e literária, analisadas no capítulo anterior. Assim, testaremos a hipótese de que os direitos autorais, como atualmente previstos em nossa legislação, foram guiados por uma visão social e econômica de arte datada do final do século XVIII e da primeira metade do século XIX, período em que havia uma clara divisão entre arte e indústria. Dessa forma, estaria justificada a distinção de tratamento jurídico de cada um desses setores, bem como as divergências entre os regimes autoralista e da propriedade industrial. Nesses dois capítulos, tentaremos averiguar (i) que ideias de autor, artista e editor foram consideradas pelos doutrinadores e legisladores brasileiros e se coincidem com o atual cenário da Economia Criativa que teremos descrito no capítulo anterior; (ii) em que medida as questões econômicas subjacentes às produções artísticas e literárias foram levadas em conta; e (iii) se a aproximação entre arte e indústria foi, em certo ponto, posta em discussão. Veremos, assim, quais teorias acerca da natureza jurídica dos direitos autorais foram sustentadas pela doutrina clássica e pelos congressistas brasileiros; bem como quais diferenças colocaram em relação à propriedade industrial; os problemas que essa divisão apresentou já com a arte aplicada; a figura romantizada de autor ao redor da qual se centraram os debates; em que extensão argumentos e interesses econômicos foram considerados; e em que medida esses interesses se identificaram na esfera internacional.

O Capítulo 3 abordará especificamente a doutrina. Iniciaremos pela história das primeiras formas modernas dos direitos autorais: o copyright inglês e o droit d'auteur 
francês - regime este adotado no Brasil. ${ }^{3}$ De igual maneira, sendo tardias tanto nossa legislação como nossa doutrina sobre o assunto, nossa pesquisa se baseará majoritariamente em trabalhos franceses, devido à influência que tiveram em nosso país.

No Capítulo 4, analisaremos os debates que antecederam a promulgação dos diplomas brasileiros que regem a propriedade intelectual, a fim de verificar em que medida as discussões contemporâneas sobre a incompatibilidade dos regimes de propriedade intelectual com a realidade contemporânea influenciaram nossa legislação sobre o tema.

No Capítulo 5 veremos quais são os problemas que a divisão da propriedade intelectual apresenta no cenário contemporâneo. Exploraremos as características de cada um desses regimes que estabelece tal descompasso, atribuindo maior proteção às obras artísticas, científicas e literárias do que aos artigos industriais. Tais elementos se observam na distinção entre os objetos de tutela de cada um dos institutos, nos seus respectivos sujeitos titulares e direitos, além das justificativas econômicas que os embasam. Nesse sentido, o caráter mais protetivo dos direitos autorais será observado nos prazos maiores de exclusividade que são concedidos sob esse regime, bem como na sua imprescindibilidade de registro e na concessão de direitos morais. A partir daí, analisaremos como esse tratamento mais restritivo (fundamentado numa visão romantizada da criação artística) faz que os direitos autorais apresentem certo anacronismo no cenário contemporâneo. Como veremos, isso se dá por quatro razões: (i) a existência de um avesso aos direitos autorais; (ii) seu tratamento como direitos de personalidade; (iii) sua configuração como direitos humanos; e (iv) a dificuldade de adaptá-los ao entorno digital. Em seguida, trataremos dos problemas que o descompasso entre direitos autorais e propriedade intelectual apresenta quando usados para tutelar artigos resultantes da aproximação entre arte e indústrias. Isso porque, como veremos, essas criações fundem elementos dos bens tradicionalmente cobertos por um ou outro instituto, o que ocasiona questionamentos sobre qual dos dois seria aplicável, com a possibilidade de sobreposição entre eles ou mesmo uma lacuna de proteção. Usaremos como exemplo a disciplina do design tanto no Brasil como na Inglaterra, onde as mudanças no cenário artístico do século XX por vezes foram consideradas na elaboração e aplicação das normas sobre a matéria. Nosso segundo

3 Por mais que esses dois regimes (copyright e droit d'auteur) apresentem suas diferenças (especialmente no foco maior deste segundo à tutela da personalidade), como ficará claro ao longo deste trabalho, por vezes observamos a ocorrência do mesmo fenômeno em ambos. Assim sendo, haverá momentos em que o termo "direitos de autor" será usado em referência também ao instituto adotado pelos países do common law. 
exemplo será o software, dotado de particularidades (e de interesses econômicos significativos por trás) que resultaram em dúvidas quanto à forma mais adequada de tutela.

O Capítulo 6 abordará as possíveis soluções para a problemática causada pela divisão entre direitos autorais e propriedade industrial. Revisaremos as críticas estabelecidas pela literatura econômica e de Law and Economics à propriedade intelectual como um todo. Então, veremos quais são as alternativas hoje sugeridas, como os creative commons, softwares livres e de código aberto, e uma extinção total da regulação de bens autorais e industriais. Nosso objetivo será avaliar se tais propostas resolvem ou não os problemas explorados neste trabalho. Em seguida, tentaremos traçar algumas diretrizes que poderão guiar futuras novas soluções. Não é, contudo, pretensão deste trabalho trazer soluções definitivas, que resolveriam completamente a questão aqui analisada. Assim, aproximamo-nos da linha dos Critical Legal Studies, focando-nos em identificar os problemas causados pela divisão da propriedade intelectual no cenário contemporâneo, bem como orientações a serem seguidas em futuras iniciativas para tratá-los. Finalizaremos essa parte analisando se os tratados internacionais relativos à propriedade intelectual dos quais o Brasil é signatário impõem restrições a tais diretrizes. ${ }^{4}$

Por fim, apresentaremos nossas conclusões no Capítulo 7.

A história da arte é fascinante. A história da propriedade intelectual, não menos. Da mesma forma, a interseção entre ambas revela uma dinâmica complexa, repleta de particularidades. Não obstante, esse tema tem ocupado menos espaço na doutrina (tanto atual como antiga) do que o merecido.

Tal lacuna parece existir em razão da tendência de se enxergar tanto a propriedade intelectual quanto a arte de forma estática: isto é, como se tivessem sempre existido de determinada maneira, dissociadas do panorama socioeconômico por trás de sua configuração em determinado momento. De igual maneira, a maior parte das obras que se dispõem a investigar a relação entre os regimes jurídicos e as questões artísticas tem como foco sobretudo a literatura, apenas margeando outras formas de expressão. Este trabalho se coloca no sentido oposto, tentando situar historicamente os direitos autorais e a

Nessa linha, sempre que nos referirmos a artigos desses tratados ou mesmo de diplomas estrangeiros mencionados, usaremos a terminologia e formatação desses documentos, de modo que o próprio termo "artigo" por vezes aparecerá iniciado em maiúscula, e por vezes será abreviado na forma de "art.", como faz a legislação brasileira. Também, a numeração será cardinal ou ordinal de acordo com o formato adotado pelo diploma em que consta. Em igual sentido, artigos de leis estadunidenses e inglesas geralmente serão introduzidos pela abreviação "s.", de section (ou "ss.", quando no plural). 
propriedade industrial numa abordagem mais ampla do fenômeno artístico, para entender a razão da incompatibilidade que apresentam no cenário contemporâneo. ${ }^{5}$

5 A quantidade de notas de rodapé talvez assuste o leitor. Assim, uma última observação é cabível antes de começarmos: este trabalho é escrito de forma a possibilitar duas leituras diferentes. O corpo do texto guarda as informações centrais exploradas aqui. No entanto, para o leitor que queira uma abordagem mais aprofundada, as notas servem para se debruçar em mais detalhes, sugerindo também outros assuntos que se relacionam aos temas nucleares desta pesquisa. 
Sobretudo, concluímos que as demais diretrizes estão em consonância com a normativa internacional, quais sejam: (1) repensar a fundamentação do regime autoralista; (2) reavaliar o sujeito de tutela; e (3) considerar os efeitos econômicos e sociais da disciplina atual e de quaisquer reformulações.

Note-se que são justamente essas três orientações que embasam as outras que elencamos acima. De igual maneira, refletem parte significativa das críticas da literatura à propriedade intelectual que apresentamos no início do capítulo, estando por trás de algumas das propostas alternativas ou substitutivas dos direitos autorais e da propriedade industrial que discutimos naquela seção. Reforçamos que não é escopo deste trabalho indicar se um sistema de direitos exclusivos sobre bens intelectuais, como um todo, é ou não o modelo mais eficiente, tanto do ponto de vista econômico como dos demais interesses sociais envolvidos. Nosso objetivo é apontar orientações a serem consideradas na busca de uma solução para a disparidade entre os direitos autorais e a propriedade industrial, bem como os problemas que causa no cenário contemporâneo.

O fato de serem hoje incompatíveis com o direito internacional da propriedade intelectual indica que algumas das diretrizes que propusemos não podem ser adotadas numa reforma doméstica. Isso não significa, porém, que não devam ser levadas em conta na relação entre os diferentes países.

Como expusemos ao longo deste trabalho, os tratados mencionados também refletem em grande parte o paradigma anterior à Economia Criativa. Desse modo, também esses acordos necessitam de adaptações à nova realidade em que vivemos. As três orientações destacadas supra (repensar a fundamentação do regime autoralista, reavaliar o sujeito de tutela e considerar efeitos econômicos e sociais) serão de suma importância nessa tarefa. Nesse sentido, servem também de ponto de partida para futuros trabalhos que se proponham a abordar as reformas necessárias à propriedade e intelectual no plano internacional.

\section{CONCLUSÃo}

Os regimes modernos da propriedade intelectual, separados em direitos autorais e propriedade industrial, surgem numa época em que predominava uma distinção marcada entre as obras artísticas - como expressões da personalidade, cujo objetivo principal não seria o comércio - e artigos utilitários, produzidos em massa para o mercado. Desse modo, 
se atribuíram características muito diferentes a cada um desses institutos, sendo a proteção autoral muito mais restritiva, devido ao caráter sacramental e personalíssimo que se reconheceu à sua criação. Ocorre que o século $\mathrm{XX}$ trouxe mudanças significativas ao cenário artístico, especialmente quanto às funções desempenhadas pela arte e à forma de seu aproveitamento econômico. Não obstante, a configuração da propriedade intelectual em duas grandes categorias apartadas manteve-se rígida, não refletindo as transformações da Economia Criativa.

No Capítulo 2, analisamos quais foram, no decorrer do tempo, os diferentes papéis atribuídos à arte: desde um instrumento de propaganda da nobreza e da Igreja, do Estado Absolutista, até, por fim, dos ideais iluministas burgueses. Vimos também que, em paralelo à evolução dessas funções, houve uma sucessão de meios de financiamento da atividade artística, como o mecenato e as Academias, que progressivamente perderam espaço à medida que se consolidaram os mercados e indústrias relativos às obras. Da mesma forma, constatamos a partir do Renascimento um movimento de libertação da arte e do artista em relação às criações utilitárias e ao comércio das obras, passando estas a serem vistas como uma expressão de sua personalidade. Esse cenário veria sua primeira ruptura com o desenvolvimento dos meios de reprodução em massa, provocando a reação Modernista. Em seguida, as Vanguardas criticariam o afastamento da arte em relação à práxis da vida cotidiana - a exemplo do Dadaísmo e dos ready-made de Duchamp. Da mesma forma, entre o final do século XIX e a primeira metade do século XX, o Arts \& Crafts, Escola de Nancy, a Art Nouveau, o De Stjl e a Bauhaus promoveram uma reaproximação de arte e indústria, visando ao desenvolvimento de ambas. Já a partir dos anos 1950, a Arte Contemporânea (em especial com o Popismo de Warhol e Lichenstein) romperia de vez com essa separação entre os dois domínios da criação humana, na medida em que não apenas abraçaria como motivos bens de consumo e adotaria técnicas de produção em massa, mas também romperia com as ideias de que o comércio não pode ser uma finalidade da arte e de que o autor não poderia se envolver diretamente nele. Assim, analisamos como nesse contexto a arte passou a apresentar as funções de entretenimento, publicidade e investimento. Ao fim do capítulo, explicamos como todas essas 
transformações descritas culminaram na chamada Economia Criativa e suas Indústrias Culturais.

Já nos Capítulos 3 e 4, tentamos identificar em que medida tais mudanças no cenário artístico se relacionam com o histórico dos regimes jurídicos usados na tutela das criações autorais. Investigamos, portanto, tanto na doutrina histórica como nos debates legislativos brasileiros (de 1822 aos dias atuais), (i) quais foram as figuras de autor, artista e editor consideradas e se correspondiam ao que observamos na Economia Criativa; e até que ponto tiveram espaço nas discussões (ii) questões econômicas; e (iii) a aproximação entre arte e indústria. Assim, estudamos as teorias que visaram a justificar a natureza jurídica do regime: migrando de um privilégio para um direito natural de propriedade limitado pela Lei por razões utilitárias - o que gerou críticas dos defensores de uma propriedade absoluta sobre as obras - e, ao longo do século XIX, um direito de personalidade, primeiramente restrito aos cidadãos do país e posteriormente estendido a estrangeiros por meio de acordos de reciprocidade e tratados). Verificamos também que os argumentos econômicos, e a romantização do autor e da atividade artística justificaram o tratamento diferenciado em relação à propriedade industrial; o que, no entanto, criou problemas no setor da arte aplicada, que então se desenvolvia. Igualmente, identificamos na doutrina e no Legislativo, por trás da visão idealizada do artista e do seu processo criativo, uma série de interesses econômicos (e também sociais) subjacentes, revelando conflitos entre grupos: autores e editores; dramaturgos e comediantes; pequenos e grandes artistas; nações produtoras e países contrafatores - este último levando à celebração de acordos no plano externo para padronização dos direitos de exclusividade.

Iniciamos o Capítulo 3 com um histórico da regulação das obras artísticas, científicas e literárias, com foco na Inglaterra e na França dos séculos XVII e XVIII berço dos dois regimes autorais modernos: respectivamente, o copyright e o droit d'auteur continental (adotado pelo Brasil). Em seguida, analisando a doutrina clássica francesa (haja vista termos incorporado a tradição daquele país sobre o tema, sendo tardias as primeiras obras nacionais relativas ao assunto), comprovamos nossa hipótese de que o direito de autor continental refletiu uma ideia de arte (seja no campo plástico ou literário) 
predominante entre o final do século XVIII e a primeira metade do século XIX principalmente no que diz respeito à sua separação em relação à indústria.

No Capítulo 4, prosseguimos com nossa investigação pelas vias legislativas brasileiras. Concluímos, então, que nossos parlamentares de forma geral seguiram a mesma linha que vimos na doutrina quanto à separação em relação à propriedade industrial e à idealização do artista: tido como indivíduo hipossuficiente e miserável, que produz por vocação. Por outro lado, os congressistas brasileiros distanciaram-se dos juristas ao serem mais pragmáticos na consideração de interesses econômicos, os quais privilegiaram em face de discussões sobre natureza jurídica e racionais filosóficos. Assim, verificamos a hipótese de que a edição dos nossos diplomas sobre o regime autoral foi pautada sobretudo por finalidades econômicas, em que pesasse o aparato filosófico usado para justificá-las. Por sua vez, concluímos ser falsa a hipótese de que o legislador não teria considerado as transformações da Economia Criativa e o surgimento da empresa-artística - exceto pela idealização do autor. Não obstante, julgamos verdadeira a hipótese principal do capítulo: a distinção entre direitos autorais e propriedade industrial, tal qual seus problemas de aplicação à realidade contemporânea não foram questionados ou discutidos pelo Legislativo.

Em seguida, exploramos no Capítulo 5 os elementos que tornam cada um desses regimes tão diferentes: (i) o objeto de tutela; (ii) o sujeito titular de direitos; (iii) a fundamentação econômica; (iv) os prazos de proteção; (v) a necessidade ou não de registro; e (vi) a atribuição de direitos morais.

A respeito do objeto, observamos uma consolidação do critério da "expressão original" (historicamente predominante do droit d'auteur e recentemente ganhando espaço diante do sweat of the brown no copyright) para que se aplique a proteção autoralista. Como vimos, porém, esse fenômeno não apenas aumenta o descompasso dos direitos autorais com a Economia Criativa (uma vez que reforça uma visão romantizada da produção artística), como também se soma a outras três frentes de expansão do instituto jurídico: a ampliação (i) do prazo, (ii) do rol de condutas, e (iii) das obras cobertas pelos direitos de exclusividade - passando paradoxalmente a tratar também de criações 
essencialmente informacionais ou tecnológicas sob o mesmo racional idealizado personalista. Em seguida, analisamos os critérios que a Lei estabelece para a aplicação da propriedade industrial - novidade, atividade inventiva e aplicação industrial para patentes, distintividade para marcas, e configuração ornamental original que possa servir de tipo de fabricação industrial para os desenhos industriais -, bem como, no cenário atual, tais características tornam-se mais difíceis de distinguir tais artigos das criações autorais. Estudamos também a crítica que se faz a outro critério diferenciador: a dicotomia ideiaexpressão.

A partir daí, vimos como o surgimento das figuras de artista-empresário e empresa-artística também esmaeceram a separação entre os sujeitos clássicos dos regimes autoralista e da propriedade industrial, especialmente com a ascensão das obras coletivas e fruto de relação de emprego, e criando uma situação controversa para a pessoa jurídica como titular derivada ou mesmo originária dos direitos autorais.

Ademais, investigamos como a divergência na justificativa econômica tradicional para cada um desses institutos (apesar de terem alguns pontos em comum, que fundamentam a propriedade intelectual como um todo) tampouco se mostra compatível com o cenário contemporâneo.

Tal racional econômico, somado à visão romantizada das criações artísticas (que teriam um elo pessoal com o seu criado), motiva o caráter mais protetivo dos direitos autorais, na forma de prazos maiores de exclusividade, imprescindibilidade do registro e a existência de direitos morais.

Esses elementos, no entanto, e seu deslocamento em relação à realidade da Economia Criativa tornam os direitos autorais anacrônicos por quatro razões. Primeiramente, por acentuarem a existência de um conflito, inerente ao regime, entre interesses do autor, da sociedade e do titular, resultando em uma aplicação desse direito ao avesso (isto é, com o predomínio dos interesses econômicos do titular sob um discurso de tutela do autor e do usuário). Isso se manifesta, por exemplo, no seu enquadramento como um direito de personalidade, causando quatro problemas principais: (i) o seu afastamento da propriedade industrial; (ii) o uso do regime autoralista para proteger não o criador 
individual, mas sim os titulares do direito; (iii) as diferenças entre os direitos autorais e os outros direitos de personalidade; e (iv) o conflito com tais outros direitos. A mesma questão também se dá ao se reconhecer os direitos autorais como direitos humanos, provocando mais quatro problemas: (i) o uso dos direitos humanos para a tutela de interesses de grandes corporações; (ii) o enrijecimento do instituto, impedindo adaptações necessárias; (iii) a possibilidade de configurar os direitos autorais como direito de propriedade, a despeito das diferenças entre eles; e (iv) o conflito com outros direitos humanos. De igual maneira, vimos que o regime autoralista se torna de difícil aplicação ao entorno digital, na medida em que reflete elementos próprios da cultura impressa, impedindo as novas formas de leitura viabilizadas pela tecnologia - formas estas criadas pelos agentes distintos dos operadores do direito: o digitalista por acidente.

A partir de então, analisamos como essa separação entre propriedade industrial e direitos autorais (causa e consequência de seu anacronismo) se manifesta problemática em dois setores limítrofes que ascenderam na Economia Criativa: o design e o software. No primeiro caso, estudamos sua regulação no Brasil e concluímos pela existência de múltiplos regimes que podem se aplicar cumulativamente, causando insegurança jurídica e, consequentemente, o risco de discrepância de tratamento na prática, com superproteção em alguns casos e ausência de tutela em outros. De igual maneira, investigamos a disciplina inglesa sobre a matéria, devido ao fato de, em uma série de momentos, ter considerado as transformações no cenário artístico e sua aproximação com a produção industrial. Ainda assim, constatamos que a escolha britânica de criar um regime sui generis não resolveu o cenário de indefinição, por duas razões: (i) o Judiciário permanece encarregado de decidir, na prática, o que é ou não arte (levando a uma série de decisões contraditórias); e (ii) essas categorias intermediárias não resolvem a discrepância entre os extremos do espectro - isto é, os direitos autorais e a propriedade industrial.

Quanto ao software, identificamos seis características que os diferenciam das criações típicas dos regimes da propriedade intelectual: (i) autoduplicidade; (ii) caráter expressivo; (iii) suporte físico; (iv) destinação funcional; (v) aproveitamento comercial; e (vi) ausência de caráter estético. Tais peculiaridades levaram a controvérsias quanto à 
forma mais adequada de discipliná-lo juridicamente. Conforme averiguamos, a pressão do lobby internacional deu maior peso às aproximações com o sistema autoralista, que passou a ser aplicado pelos países. Nesse sentido, o Brasil acabou por formalmente atribuir-lhe tal proteção, mas com algumas particularidades que, na prática, criaram uma tutela sui generis. Ainda assim, persiste a possibilidade de cumulação com outras categorias da propriedade intelectual, demonstrando a defasagem da estrutura bipolar na época atual.

Já no Capítulo 6, investigamos possíveis soluções para os problemas causados pela dificuldade de aplicação da separação entre direitos autorais e propriedade industrial. Começamos pela revisão da crítica econômica à propriedade intelectual, segundo a qual esse regime provocaria: (i) a tragédia dos anticomuns (por serem os bens imateriais de baixa rivalidade e poder de exclusão); (ii) aumento de custos de transação; (iii) retardamento, em vez de estímulo, à inovação; (iv) manutenção de poder de mercado, em vez de fomentar a concorrência. Além disso, as justificativas econômicas frequentemente ignorariam: (a) que existem outras formas de agentes tirarem proveito financeiro de suas inovações, que não pela exclusividade; (b) que há motivações não pecuniárias para criar; e (c) que a regulação de bens intelectuais diz respeito a outros interesses que não estritamente econômicos.

A partir daí, expusemos os modelos alternativos que se propõem tanto para os direitos autorais como para a propriedade industrial. Assim, constatamos que nem os creative commons, nem o software livre, nem o código aberto, nem mesmo abolição completa da propriedade intelectual (ou substituição por um regime de recompensas) endereçam adequadamente a problemática central deste trabalho: a dificuldade de adaptação da divisão clássica dos regimes à atualidade.

Não sendo, entretanto, nosso objetivo apresentar uma resposta final a esse problema, mas sim propor uma análise crítica, elaboramos sete diretrizes para eventuais iniciativas que visem a solucionar a questão: (i) atualizar a fundamentação desses institutos; (ii) repensar os sujeitos de tutela; (iii) repensar o enquadramento dos direitos autorais como direitos humanos e de personalidade; (iv) repensar os direitos morais (uma vez que são melhor abarcados por outros direitos humanos e de personalidade já 
reconhecidos, ou por normas de interesse público, como a tipificação da falsidade ideológica); (v) repensar a própria forma de categorização dos objetos e respectivas formas de tutela (o que poderia ser feito de acordo com o mercado em que comercializada no caso concreto); (vi) repensar prazos e registro facultativo (podendo ser prazos curtos, extensíveis de acordo com a renovação do registro, que poderia também ser pedido para mercados específicos, como funciona hoje com as marcas); e (vii) considerar os efeitos econômicos e sociais (de modo que Legislativo e Judiciário se atentem para evidências empíricas das prováveis consequências de suas decisões, identificando, para tanto, os interesses de diversos grupos da sociedade que serão afetados - o que pode ser obtido por meio de uma maior participação popular nos debates, tal como se observou no caso canadense).Entretanto, apontamos algumas limitações às diretrizes supramencionadas nos tratados internacionais sobre a propriedade intelectual dos quais o Brasil é parte. Porém, três das nossas orientações principais (repensar a fundamentação do regime autoralista, reavaliar o sujeito de tutela e considerar os efeitos econômicos e sociais da disciplina atual e de quaisquer reformulações) não encontram tais restrições, podendo ser adotadas no plano doméstico. Mais ainda, podem também servir de guia (assim como as demais diretrizes) para eventuais reformas no âmbito internacional, haja vista que também os tratados incorporam essa divisão clássica da propriedade intelectual em direitos autorais e propriedade industrial, embasados numa visão socioeconômica que já não encontra respaldo no cenário contemporâneo.

Em suma, provamos verdadeira a hipótese central deste trabalho. Isto é, confirmamos ao longo desta pesquisa que as dificuldades de se aplicarem os regimes da propriedade intelectual na Economia Criativa (tais como expostas no Capítulo 5) são causadas pelo descompasso entre a visão antiga de arte em que se baseiam e um novo modelo de financiamento e produção difundido a partir da segunda metade do século passado. Em outras palavras, a separação em duas grandes categorias (uma para as obras artísticas, mais protetiva; e outra para criações utilitárias e comerciais, juridicamente menos rigorosa), tanto no âmbito interno como nos tratados internacionais, não considera de uma forma ampla as transformações sociais e econômicas que vimos observando nos mercados artísticos, tal como discorridas no Capítulo 2. 
Nesse sentido, a contribuição final deste trabalho - cerne das diretrizes que propomos -, consiste em provocar uma mudança na forma de se pensar globalmente a propriedade intelectual, desafiando o paradigma clássico que se cristalizou na legislação, na doutrina e na jurisprudência nos últimos 250 anos. Como expusemos no Capítulo 2, a arte mudou; indústrias surgiram: a figura do artista se reinventou, os meios de financiamento se transformaram, enquanto novos mercados se tornaram viáveis. O Direito, portanto, também pode e deve se atualizar. 


\section{REFERÊNCIAS}

ADORNO, Theodor W. Aesthetic Theory. Trad. The Athlone Press Ltd. Londres/Nova York: Continuum, 2002.

; HORKHEIMER, Max. Dialética do esclarecimento: fragmentos filosóficos. Rio de Janeiro: Jorge Zahar, 1985.

ALBUQUERQUE, Eduardo da Motta e. A política norte-americana e os direitos de propriedade industrial: uma discussão introdutória sobre as razões da ofensiva por legislações mais rigorosas. Belo Horizonte: UFMG/CEDEPLAR, 1995.

ALENCAR, José de. A propriedade. Brasília: Senado Federal, 2004. Disponível em: $<$ http://bit.ly/alencar-prop>. Último acesso em: 10 dez. 2018.

AMARAL, Francisco. Direito civil: introdução. 8. ed. rev., atual. e aum. Rio de Janeiro: Renovar, 2014.

ANDERSEN, Birgitte. How technology changes the scope, strenght and usefulness of copyright - revisiting the economic rationales. In: MACMILLAN, Fiona (Org.). New Directions in Copyright Law. Cheltenham: Edward Elgar, 2007. vol. 5.

ANNAES do Senado Brazileiro. $1^{\text {a }}$ sessão da $20^{\text {a }}$ legislatura. Vol. V: de 1 a 30 de setembro-de 1 a 16 de outubro. Rio de Janeiro: Typographia Imperial e Constitucional de J. Villeneuve \& C., 1886. Disponível em: <http://bit.ly/anais1886t5>. Último acesso em: 14 dez. 2018.

ANNAES do Senado do Imperio Brazileiro. $4^{\mathrm{a}}$ sessão da $15^{\mathrm{a}}$ legislatura. Vol. V: setembro, outubro e appendice. Parte I. Rio de Janeiro: Typographia do Diário do Rio de Janeiro, 1875. Disponível em: <http://bit.ly/anais1875t6>. Último acesso em: 14 dez. 2018.

. $4^{\mathrm{a}}$ sessão da $15^{\mathrm{a}}$ legislatura. Vol. V: setembro, outubro e appendice. Parte II. Rio de Janeiro: Typographia do Diário do Rio de Janeiro, 1875. Disponível em: $<$ http://bit.ly/anais1875t7>. Último acesso em: 14 dez. 2018.

ANNAES do Senado do Imperio do Brazil. Segunda sessão da primeira legislatura. Tomo Primeiro: de 8 de março a 25 de junho de 1829. Rio de Janeiro, 1914. Disponível em: $<$ http://bit.ly/anais1829>. Último acesso em: 14 dez. 2018.

- Terceira sessão em 1871 da décima quarta legislatura. Vol. V: de 1 a 30 de setembro. Rio de Janeiro: Typographia do Diario do Rio de Janeiro, 1871. Disponível em: < http://bit.ly/anais1871v5>. Último acesso em: 14 dez. 2018. 
. Segunda sessão da décima quinta legislatura. Vol. III: de 1 a 31 de julho de 1873 . Rio de Janeiro: Typographia do Diario do Rio de Janeiro, 1873. Disponível em: $<$ http://bit.ly/anais1873t4>. Último acesso em: 14 dez. 2018.

AOKI, Keith. (Intellectual) Property and Sovereignty: Notes toward a Cultural Geography of Authorship. Stanford Law Review, vol. 48, n. 5, p. 1.293-1.355, maio 1996. Disponível em: <http://bit.ly/aoki1996>. Último acesso em: 10 dez. 2018.

ARROW, Kenneth. Economic Welfare and the Allocation of Resources for Invention. In: NBER. The Rate and Direction of Inventive Activity: Economic and Social Factors. Princeton University Press: 1962. Disponível em: <http://bit.ly/arrow1962>. Último acesso em: 15 dez. 2018.

ASCARELLI, Tullio. Teoría de la concurrencia y de los bienes inmateriales. Trad. Evelio Verdera e Luis Suárez-Llanos. 3. ed. Barcelona: Bosch, 1970.

ASCENSÃO, José de Oliveira. Direito autoral. 2. ed. Rio de Janeiro: Renovar, 1997.

. Programa de computador e direito autoral. In: GOMES, Orlando et al. (Org.). $A$ proteção jurídica software. Rio de Janeiro: Forense, 1985.

ASSEMBLÉA CONSTITUINTE. Annaes do Parlamento Brazileiro: 1823. Tomo Terceiro. Rio de Janeiro: 1878. Disponível em: <http://bit.ly/anais1823t3>. Último acesso em: 14 dez. 2018.

. Annaes do Parlamento Brazileiro: 1823. Tomo Quarto. Rio de Janeiro: 1879. Disponível em: < http://bit.ly/anais1823t4>. Último acesso em: 14 dez. 2018.

ASSEMBLEIA NACIONAL CONSTITUINTE. Atas de Comissões. 1987. Disponível em: $<$ http://bit.ly/assembleia1987>. Último acesso em: 14 dez. 2018.

AYUSO, Rocío. La compañía adquiere el imperio de George Lucas por 3.125 millones de euros. El País. 31 out. 2012. Disponível em: <http://bit.ly/elpais2012>. Último acesso em: 15 dez. 2018.

AZEVEDO NETO, Joachin. A noção de autor em Barthes, Foucault e Agamben. Floema, ano VIII, n. 10, p. 153-164, jan.-jun. 2014.

BAILly, Gustavo Adolpho. Protection des inventions au Brésil. 2. ed. Paris: Giard \& Brière, 1915.

BALLARDINI, Rosa Maria. Scope of IP Protection for the Functional Elements of Software. In: IPR UNIVERSITY CENTER. In Search of New IP Regimes. Helsinki: Oy Nord Print Ab, 2010. 
BALZAC, Honoré de. Lettre adressée aux écrivains français du XIXe siècle. Revue de Paris, Nouvelle Série, tomme XI, 1834. Disponível em: <http://goo.gl/SRyrpH>. Último acesso em: 13 dez. 2018.

BARBOSA, Denis Borges. A proteção do software. Disponível em: $<$ http://bit.ly/barbosa2001>. Último acesso em: 15 dez. 2018.

. Uma introdução à propriedade intelectual. 2. ed. Rio de Janeiro: Lumen Iuris, 2003. Disponível em: <http://bit.ly/denisborgesbarbosa>. Último acesso em: $14 \mathrm{dez}$. 2018.

BARTHES, Roland. A morte do autor. In: O rumor da língua. Trad. Mário Laranjeira. 2. ed. São Paulo: Martins Fontes, 2004.

BASSO, Maristela. A tutela constitucional da propriedade intelectual na Carta de 1988: avanço indiscutível. Revista de Informação Legislativa, Brasília, vol. 45, n. 179, p. 3941, jul.-set. 2008. Disponível em: <http://bit.ly/basso2008>. Último acesso em: 15 dez. 2018.

BASTIAT, Frédéric. Discours au cercle de la librairie en 16 décembre 1847. In:

Oeuvres completes. Paris: Éditions Guillaumin, 1862. vol. 2. Disponível em: $<$ http://bit.ly/bastiat1847>. Último acesso em: 13 dez. 2018.

BAUMOL, William Jack; BOWEN, William Gordon. On the Perfoming Arts: The Anamoty of Their Economic Problems. The American Economic Review, vol. 55, n. 1/2, p. 495-502, mar. 1965. Disponível em: <http://bit.ly/baumon-bowen2006>. Último acesso em: 14 fev. 2016.

BEAUMARCHAIS, Pierre-Augustin Caron de. Compte rendu de l'affaire des auteurs dramatiques et des comédiens français. Oeuvres complètes de Beaumarchais. Paris: Furne, 1826. vol. 6. Disponível em: <http://goo.gl/nlYh4A>. Último acesso em: 8 jul. 2016.

BECKER, Howard S. Mundos da arte. Edição comemorativa do $25^{\circ}$ aniversário, revista e aumentada. Trad. Luís San Payo. Lisboa: Livros Horizonte, 2010.

BENHAMOU, Françoise. A economia da cultura. Trad. Geraldo Gerson de Souza. Cotia: Ateliê Editorial, 2007.

BENJAMIN, Walter. A obra de arte na época de suas técnicas de reprodução. Trad. José Lino Grünnewald. São Paulo: Abril, 1975.

BENKLER, Yochai. Coase's Penguin, or, Linux and The Nature of the Firm. The Yale Law Journal, vol. 112, n. 3, dec. 2002. Disponível em: <http://bit.ly/benkler2002>. Último acesso em: 15 dez. 2018. 
BENTLY, Lionel. R. v. the Author: From Death Penalty to Community. Columbia Journal of Law \& the Arts, vol. 32, 2008.

. Review Article: Copyright and the Death of the Author in Literature and Law. The Modern Law Review, vol. 57, p. 973-986, nov. 1994.

. The Design/Copyright Conflict in the United Kingdom: A History. In: DERCLAYE, Estelle. (Org.). The Copyright/Design Interface: past, present and future. Nova York: Cambridge University Press, 2018.

. The Return of Industrial Copyright? European Intellectual Property Review, p. 654-672, 2012. Disponível em: <http://bit.ly/bently2012>. Último acesso em: 15 dez. 2018.

; SHERMAN, Brad. The Making of Modern Intellectual Property Law: The British Experience, 1760-1911. Cambridge: Cambridge University Press, 2003.

BESSEN, James; MEURER, Michael J. Patent Failure: How Judges, Bureaucrats, and Lawyers Put Innovators at Risk. Princeton and Oxford: Princeton University Press, 2008.

BITTAR, Carlos Alberto. Direito de autor. 5. ed. rev., atual. e ampl. por Eduardo C. B. Bittar. Rio de Janeiro: Forense Universitária, 2013.

. Direito de autor na obra publicitária. São Paulo: Revista dos Tribunais, 1981.

. Os direitos de personalidade. 2. ed. São Paulo: Forense Universitária, 1995.

. Enquadramento jurídico do "hardware" e do "software" no plano dos direitos intelectuais. Revista de Informação Legislativa, vol. 19, n. 73, p. 307-326, jan.-mar. 1982. Disponível em: <http://bit.ly/senadosoftw>. Último acesso em: 15 dez. 2018.

BIZUTTI ANDRADE, Andressa. Os desafios regulatórios das aplicações OTT de vídeo: vídeo sob demanda e plataformas de compartilhamento. 2016. Monografia (Trabalho de conclusão do curso). Orientador: Prof. Doutor Carlos Pagano Botana Portugal Gouvêa - Faculdade de Direito da Universidade de São Paulo, São Paulo.

BLACKSTONE, William. An Enquire in the Nature and Origins of Litterary Property. Londres: William Flexney, 1762. Disponível em: <http://bit.ly/blackstone1762>. Último acesso em: 20 nov. 2018.

BLANC, Étienne. Traité de la contrefaçon et de sa poursuite en justice. Paris, 1838. Disponível em: <http://bit.ly/blanc1838>. Último acesso em: 13 dez. 2018.

BLANC, Louis. Organisation du Travail. 5. ed. Paris: Bureau de la Société de l'Industrie Fraternelle, 1847. Disponível em: <http://bit.ly/blanc1847>. Último acesso em: 14 dez. 2018. 
BLONDEL, Pierre-Jacques. Mémoire sur les vexations qu'exercent les libraires \& imrpimeurs de Paris. [1725 ou 1726]. Disponível em: <http://goo.gl/GNdZGI>. Último acesso em: 8 jul. 2016.

BOLAÑO, César. Mercado de arte: novas e velhas questões. In: et al. (Org.). Economia da arte e da cultura. São Paulo: Itaú Cultural, 2010. Disponível em: $<$ http://bit.ly/bolano2010>. Último acesso em: 22 dez. 2016.

BOLDRIN, Michele; LEVINE, David K. Against Intellectual Monopoly. Cambridge: Cambridge University Press, 2008. Disponível em: <http://bit.ly/boldrin2008 >. Último acesso em: 15 dez. 2018.

BOOTON, David L. Art in ohe Law of Copyright: Legal Determinations of Artistic Merit Under United Kingdom Copyright Law. Art, Antiquity and Law, vol. I, n. 2, p. $125-$ 139, maio 1996.

BORGES, Jorge Luis. La Biblioteca de Babel. In: . Ficciones. Barcelona: Alianza Editorial, 1998.

BORGHI, Maurizio. Chasing Copyright Infringement in the Streaming Landscape. International Review of Intellectual Property and Competition Law, vol. 42, n. 3, p. 316-343, 2011.

BOSSANGE, Hector. Opinion nouvelle sur la propriété littéraire. Imprimerie de Rignoux, 1836. Disponível em: <http://bit.ly/bossange1836a>. Último acesso em: 13 dez. 2018.

BOUFFLERS, Stanislas Jean de. Rapport fait à l'Assemblée Nationale au nom du Comité d'Agriculture et de Commerce: dans la séance du jeudi au soir 30 décembre 1790, sur la propriété des auteurs de nouvelles découvertes \& inventions en tout genre d'industrie imprimé par ordre de l'Assemblée Nationale. Paris: L'Imprimerie Nationale, 1791. Disponível em: <http://bit.ly/boufflers1791>. Último acesso em: 13 dez. 2018.

BOURDIEU, Pierre. As regras da arte: gênese e estrutura do campo literário. Trad. Maria Lúcia Machado. São Paulo: Companhia das Letras, 2010.

BOWREY, Kathy. Ethical boundaries and internet cultures. In: BENTLY, Lionel; MANIATIS, Spyros M. (Org.). Intellectual property and ethics. London: Sweet \& Maxwell, 1998.

BOYLE, James. Shamans, Software, and Spleens: law and the construction of the information society. Cambridge: Harvard University Press, 1996.

. The second enclosure movement and the construction of the public domain. Law and Contemporary Problems, vol. 66, p. 33-74, 2003. Disponível em: $<$ http://bit.ly/boyler2003>. Último acesso em: 15 dez. 2018. 
BRACHA, Oren. The Ideology of Authorship Revisited: Authors, Markets, and Liberal Values in Early American Copyright. The Yale Law Journal, vol. 118, n. 2, p. 186-271, nov. 2008. Disponível em: <http://bit.ly/bracha2008>. Último acesso em: $18 \mathrm{dez}$. 2018.

BRITISH COUNCIL. Mapping the creative industries: the UK context. Londres, 2005.

BÜRGER, Peter. Theory of the avant-garde. Trad. Suhrkamp Verlag. Manchester: Manchester University Press, 1984.

BURK, Dan L.; LEMLEY, Mark A. The Patent Crisis and How the Courts Can Solve It. Chicago e Londres: The University of Chicago Press, 2009.

BURREL, Roberto. A Case Study in Cultural Imperialism: The Imposition of Copyright on China by the West. In: BENTLY, Lionel; MANIATIS, Spyros M. (Org.). Intellectual property and ethics. London: Sweet \& Maxwell, 1998.

CALMELS, Édouard. De la propriété et de la contrefaçon des oeuvres de l'intelligence. Paris: Çosse, 1856. Disponível em: <http://bit.ly/calmels1856>. Último acesso em: 13 dez. 2018.

CAMARA DOS SRS. DEPUTADOS. Annaes do Parlamento Brazileiro: primeiro anno da decima legislatura, sessão de 1857. Tomo 5. Rio de Janeiro: Typographia Imperial e Constitucional de J. Villeneuve \& Co, 1857. Disponível em: $<$ http://bit.ly/anais1857t5>. Último acesso em: 14 dez. 2018.

- Annaes do Parlamento Brazileiro: quarto anno da decima-quinta legislatura, sessão de 1875. Tomo III. Rio de Janeiro: Typographia Imperial e Constitucional de J. Villeneuve \& Co, 1875.

CARBONI, Guilherme. Direito autoral e autoria colaborativa na economia da informação em rede. São Paulo: Quartier Latin, 2010.

O direito de autor na multimídia. São Paulo: Quartier Latin, 2003.

CARTER-SILK, Alexander; LEWISTON, Michelle. The Development of Design Law Past and Future: From History to Policy. Newport: The Intellectual Property Office, 2012. Disponível em: <http://bit.ly/silk-lewiston>. Último acesso em: 15 dez. 2018.

CAUQUELIN, Anne. Arte contemporânea: uma introdução. Trad. Rejane Janowitzer. São Paulo: Martins Fontes, 2008.

CHAGAS, Manuel Pinheiro. A Propriedade Litteraria: carta a sua magestade o Imperador do Brazil. Porto: Ernesto Chardron, 1879. 
CHARTIER, Roger. Figures of the Author. In: SHERMAN, Brad; STROWEL, Alain. (Org.). Of Authors and Origins: Essays on copyright law. Oxford: Clarendon Press, 1994.

CHINELLATO, Silmara Juny de Abreu. Direito de autor e direitos da personalidade: reflexões à luz do Código Civil. 2008. Tese (Concurso para professor titular de Direito Civil) - Faculdade de Direito da Universidade de São Paulo. São Paulo.

COASE, Ronald H. The Nature of the Firm. Economica, New Series, vol. 4, n. 16, p. 386405, nov. 1937. Disponível em: <http://bit.ly/coase1937a>. Último acesso em: 22 dez. 2016 .

COMITÉ DE LA ASSOCIATIÓN POUR LA DÉFENSE DE LA PRORIÉTÉ LITTÉRAIRE. De l'application du droit commun à la propriété littéraire et artistique. Paris: Hachette, 1862. Disponível em: <http://goo.gl/JZZu8G>. Último acesso em: 8 jul. 2016.

. La propriété littéraire et artistique. Paris: Hachette, 1862. Disponível em: $<$ http://goo.gl/PwA3Rl>. Último acesso em: 8 jul. 2016.

COMPARATO, Fábio Konder. A afirmação histórica dos direitos humanos. 7. ed. São Paulo: Saraiva, 2010.

O direito e o avesso. Estudos Avançados, vol. 23, n. 67, p. 6-22, 2009. Disponível em: <http://bit.ly/comparato2009>. Último acesso em: 22 dez. 2018.

CONDORCET, Jean-Antointe-Nicolas de Caritat. Oeuvres Complètes de Condorcet. Paris: Henrichs, 1804. vol. 16. Disponível em: <http://bit.ly/condorcet1776>. Último acesso em: 10 dez. 2018.

CONGRESSO NACIONAL. Anais do Senado Federal: Agosto de 1976, $126^{\mathrm{a}}$ a $139^{\mathrm{a}}$ sessões. Brasília: Subsecretaria de Anais, 1976. vol. II. Disponível em: $<$ http://bit.ly/anais1976>. Último acesso em: 14 dez. 2018.

. Anais do Senado Federal: Atas da $40^{\mathrm{a}}$ à $49^{\mathrm{a}}$ Sessão da $1^{\mathrm{a}}$ Sessão Legislativa Ordinária da 50 ${ }^{\mathrm{a}}$ Legislatura. Vol. 19, n. 7 (17 abril a 28 abril 1995). Brasília: Secretaria de Documentação e Informação - Subsecretaria de Anais - Senado Federal, 1995. Disponível em: <http://bit.ly/anais1995t7>. Último acesso em: 14 dez. 2018.

. Anais do Senado Federal: Atas da $8^{\mathrm{a}}$ à $14^{\mathrm{a}}$ Sessão da $6^{\mathrm{a}}$ Sessão Legislativa Extraordinária da 50a Legislatura. Vol. 22, no 2 (16 jan. a 26 jan. 1998). Brasília: Secretaria de Documentação e Informação - Subsecretaria de Anais - Senado Federal, 1998. Disponível em: <http://bit.ly/anais1998>. Último acesso em: 14 dez. 2018.

Anais do Senado Federal: Atas da $157^{\mathrm{a}}$ à $160^{\mathrm{a}}$ Sessão da $1^{\mathrm{a}}$ Sessão Legislativa Ordinária da 52a Legislatura. Vol. 27, n. 40 (6 nov. a 11 nov.). Brasília: Senado 
Federal - Secretaria Especial de Editoração e Publicações - Subsecretaria de Anais, 2003. Disponível em: <http://bit.ly/anais2003>. Último acesso em: 14 dez. 2018.

Anais do Senado Federal: Atas da $22^{\mathrm{a}}$ à $25^{\mathrm{a}}$ Sessão da $3^{\mathrm{a}}$ Sessão Legislativa Ordinária da 52a Legislatura. Vol. 29, n. 7 (17 mar. a 22 mar.). Brasília: Senado Federal - Secretaria Especial de Editoração e Publicações - Subsecretaria de Anais, 2005. Disponível em: <http://bit.ly/anais2005t7>. Último acesso em: 14 dez. 2018.

Anais do Senado Federal: Atas da $217^{\mathrm{a}}$ à $220^{\mathrm{a}}$ Sessão da $3^{\mathrm{a}}$ Sessão Legislativa Ordinária da 52a Legislatura. Vol. 29, n. 57 (7 dez. a 9 dez.). Brasília: Senado Federal

- Secretaria Especial de Editoração e Publicações - Subsecretaria de Anais, 2005. Disponível em: <http://bit.ly/anais2005t57>. Último acesso em: 14 dez. 2018.

Anais do Senado Federal: Atas da $223^{\mathrm{a}}$ à $225^{\mathrm{a}}$ Sessão da $3^{\mathrm{a}}$ Sessão Legislativa Ordinária da 52 ${ }^{\mathrm{a}}$ Legislatura. Vol. 29, n. 59 (14 dez. a 15 dez.). Brasília: Senado Federal - Secretaria Especial de Editoração e Publicações - Subsecretaria de Anais, 2005. Disponível em: <http://bit.ly/2005t59>. Último acesso em: 14 dez. 2018.

Anais do Senado Federal: Atas da $1^{\mathrm{a}}$ à $2^{\mathrm{a}}$ Sessão da $5^{\mathrm{a}}$ Sessão Legislativa Extraordinária da 52a Legislatura. Vol. 30, n. 1 (16 jan. a 17 jan.). Brasília: Senado Federal - Secretaria Especial de Editoração e Publicações - Subsecretaria de Anais, 2006. Disponível em: <http://bit.ly/anais2006>. Último acesso em: 14 dez. 2018.

. Anais do Senado Federal: Atas da 248 ${ }^{a}$ Sessão da $3^{a}$ Sessão Legislativa Ordinária da 53 ${ }^{\text {a }}$ Legislatura. Vol. 33, n. 94-A (16 de dezembro). Brasília: Senado Federal Secretaria Especial de Editoração e Publicações - Subsecretaria de Anais, 2009. Disponível em: <http://bit.ly/anais2009>. Último acesso em: 14 dez. 2018.

. Anais do Senado Federal: Ata da $88^{\mathrm{a}}$ Sessão da $1^{\mathrm{a}}$ Sessão Legislativa Ordinária da $54^{\mathrm{a}}$ Legislatura. Vol. 35, n. 35 ( $1^{\mathrm{o}}$ de junho). Brasília: Senado Federal - Secretaria Especial de Editoração e Publicações - Subsecretaria de Anais, 2011. Disponível em: $<$ http://bit.ly/anais2011>. Último acesso em: 14 dez. 2018.

. Annaes da Camara dos Deputados: terceira sessão da primeira legislatura. Vol. II: Sessões de 1 a 30 de junho de 1893. Rio de Janeiro: Imprensa Nacional, 1893. Disponível em: <http://bit.ly/anais1893t2a>. Último acesso em: 14 dez. 2018.

. Annaes da Camara dos Deputados: terceira sessão da primeira legislatura. Vol. III: Sessões de 1 a 31 de julho de 1893. Rio de Janeiro: Imprensa Nacional, 1893. Disponível em: <http://bit.ly/anais1893t3>. Último acesso em: 14 dez. 2018.

Annaes da Camara dos Deputados: terceira sessão da primeira legislatura. Vol. IV: Sessões de 1 a 31 de agosto de 1893. Rio de Janeiro: Imprensa Nacional, 1893. Disponível em: <http://bit.ly/anais1893t4>. Último acesso em: 14 dez. 2018. 
. Annaes da Camara dos Deputados: terceira sessão da primeira legislatura. Vol. IV: Sessões de 1 a 31 de agosto de 1894. Rio de Janeiro: Imprensa Nacional, 1895. Disponível em: <http://bit.ly/anais1894t4>. Último acesso em: 14 dez. 2018.

. Annaes da Camara dos Deputados: terceira sessão da primeira legislatura. Vol. V: Sessões de 1 a 31 de agosto de 1894. Rio de Janeiro: Imprensa Nacional, 1895. Disponível em: <http://bit.ly/anais1894t5>. Último acesso em: 14 dez. 2018.

. Annaes da Camara dos Deputados: segunda sessão da quarta legislatura. Vol. IV (Appendice): Receita Geral (Parecer). Rio de Janeiro: Imprensa Nacional, 1901. Disponível em: <http://bit.ly/anais1901t4>. Último acesso em: 14 dez. 2018.

. Annaes da Camara dos Deputados: sessão extraordinária. Vol. I: Sessões de 19 a 28 de fevereiro de 1902. Rio de Janeiro: Imprensa Nacional, 1902. Disponível em: $<$ http://bit.ly/anais1902t1>. Último acesso em: 14 dez. 2018.

. Annaes da Camara dos Deputados: sessão extraordinária. Vol. II: Sessões de 3 a 31 de março de 1902. Rio de Janeiro: Imprensa Nacional, 1902. Disponível em: $<$ http://bit.ly/anais1902t12>. Último acesso em: 14 dez. 2018.

. Annaes da Camara dos Deputados. Vol. VI: Sessões de 2 a 30 de outubro de 1911. Rio de Janeiro: Typographia do Jornal do Commercio, de Rodrigues \& C., 1914. Disponível em: <http://bit.ly/anais1911t6>. Último acesso em: 14 dez. 2018.

. Annaes da Camara dos Deputados. Vol. VII: Sessões de 1 a 17 de novembro de 1911. Rio de Janeiro: Typographia do Jornal do Commercio, de Rodrigues \& C., 1914. Disponível em: <http://bit.ly/anais1911t7>. Último acesso em: 14 dez. 2018.

Annaes da Camara dos Deputados: convocação extraordinária de 2 de Abril de 1913. Vol. II (Apprendice): Projecto n. 2, de 1913 - Emendas do Senado ao projecto da Camara, n. 1, de 1902 - Codigo Civil Brazileiro. Rio de Janeiro: Imprensa Nacional, 1913. Disponível em: <http://bit.ly/anais1913t2>. Último acesso em: $14 \mathrm{dez}$. 2018.

. Annaes da Camara dos Deputados. Vol. XI: Sessões de 14 a 30 de novembro de 1917. Rio de Janeiro: Imprensa Nacional, 1919. Disponível em: $<$ http://bit.ly/anais1917t11>. Último acesso em: 14 dez. 2018.

- Annaes do Senado Federal: terceira sessão da segunda legislatura. Vol. V: Sessões de 15 de outubro a 14 de outubro de 1896. Rio de Janeiro: Imprensa Nacional, 1897. Disponível em: <http://bit.ly/anais1896t5>. Último acesso em: 14 dez. 2018.

. Annaes do Senado Federal. Vol. VII: Sessões de 1 a 14 de novembro de 1923. Rio de Janeiro: Imprensa Nacional, 1927. Disponível em: <http://bit.ly/anais1923t7>. Último acesso em: 14 dez. 2018. 
COOMBE, Rosemary J. The cultural life of intellectual properties: authorship, appropriation and the law. Durham e Londres: Duke University Press, 2008.

CORBET, Jan. Allocution de bienvenue. In: BRISON, Fabienne et al. (Org.). Moral Rights in the $21^{\text {st }}$ Century. Bruxelas: Larcier, 2015.

CORDEIRO, Antônio Menezes. Tratado de direito civil português. Coimbra: Almedina, 2007.

CUNNINGHAM, Stuart D. From cultural to creative industries: theory, industry, and policy implications. Media International Australia Incorporating Culture and Policy: Quarterly Journal of Media Research and Resources, n. 102, p. 54-65, fev. 2002. Disponível em: <http://eprints.qut.edu.au/588/> Último acesso em: 15 fev. 2015.

DANTO, Arthur C. After the end of art: contermporary art and the pale of history. Princeton: Princeton University Press, 1997.

Art, Evolution and the Consciousness of History. The Journal of Aesthetics and Arts Criticism, vol. 44, n. 33, p. 223-233, 1986.

. The Art World. The Journal of Philosophy, vol. 61, n. 19, American Philosophical Association Eastern Division Sixty-First Annual Meeting (Oct. 15, 1964), p. 571-584. Disponível em: <http://bit.ly/danto1964>. Último acesso em: 10 dez. 2018.

. The Transfiguration of the Common Place: A Philosophy of Art. Cambridge e Londres: Harvard University Press, 1981.

. What is art. New Haven e Londres: Yale University Press, 2013.

DARWIN, Charles. The Origin of the Species. Ware: Wordsworth, 1997.

DAVIES, Gillian; GARNETT, Kevin. Moral Rights. 2. ed. Londres: Sweet and Maxell, 2016.

DE MOLINARI, Gustave. Propriété Artistique. In: COQUELIN, Charles; GUILLAUMIN, Gilbert. Dictionnaire de l'économie politique. 1853. vol. 2. Disponível em: $<$ http://bit.ly/demolinari1853>. Último acesso em: $13 \mathrm{dez} .2018$.

DEFOE, Daniel. An Essay on the Regulation of the Press. Londres, 1704. Disponível em: $<$ http://bit.ly/defoeessay>. Último acesso em: 20 nov. 2018.

DELASALLE, Jules. Thése de doctorat sur la propriété littéraire soutenue devant la Faculté de Pars le 11 novembre 1852, à midi et demi. Paris: Thunot, 1852. Disponível em: <http://goo.gl/jst48f>. Último acesso em: 8 jul. 2016. 
DERCLAYE, Estelle. A Model Copyright/Design Interface: Not and Impossible and Undesirable Task? In: . (Org.). The Copyright/Design Interface: past, present and future. Nova York: Cambridge University Press, 2018.

DESBOIS, Henri. Le droit d'auteur: droit français, Convention de Berne revisée. Paris: Dalloz, 1950.

D'HÉRICOURT, Louis. Memorandum à Monseigneur le Garde des Sceaux. 1726. Disponível em: <http://goo.gl/HxA6dw>. Último acesso em: 8 jul. 2016.

DIDEROT, Denis. Lettre sur le commerce des livres. 1763. Disponível em: $<$ http://bit.ly/diderot1763>. Último acesso em: $10 \mathrm{dez} .2018$.

DIDOT, Ambroise-Firmin. Note sur la propriété littéraire et sur la répression des contrefaçons faites à l'étranger, particulierement en Belgique. [1836?]. Disponível em: <http://goo.gl/v5vPMk>. Último acesso em: 8 jul. 2016.

DOUEIHI, Milad. La gran conversión digital. Buenos Aires: Fondo de Cultura Económica, 2010.

DRAHOS, Peter. A Philosophy of Intellectual Property. Acton: ANU eTEXT, 2016. Disponível em: <http://bit.ly/drahos2016>. Último acesso em: 14 dez. 2018.

DREYFUSS, Rochelle C. Does Ip Need Ip? Accommodating Intellectual Production Outside The Intellectual Property Paradigm. Cardozo Law Review, vol. 31, n. 5, p. $1.437-1.473,2010$.

DU MONT, Jason J.; JANIS, Mark D. US Design Patent Law: A Historical Look at the Design Patent/Copyright Interface. In: DERCLAYE, Estelle. (Org.). The Copyright/Design Interface: past, present and future. Nova York: Cambridge University Press, 2018.

DUPUIT, Jules. Du principe de propriété: Le juste - 1'utile. Journal des Economistes, $2^{\text {ème }}$ série, vol. 29, 1861, p. 321-347. Disponível em: <http://bit.ly/dupuit1861>. Último acesso em: 13 dez. 2018.

DUSOLLIER, Séverine. Intellectual property and the bundle-of-rights metaphor. Kritika, vol. 4, 2019. No prelo.

Sharing Access to Intellectual Property Through Private Ordering. Chicago-Kent Law Review, vol. 82, n. 3, p. 1.391-1.435, 2007. Disponível em: $<$ http://bit.ly/dusollier2007>. Último acesso em: 15 dez. 2018.

. The Master's Tools v. The Master's House: Creative Commons v. Copyright. Columbia Journal of Law \& the Arts, vol. 29, n. 3, p. 271-293, 2006. Disponível em: $<$ http://bit.ly/dusollier2006>. Último acesso em: 15 dez. 2018. 
EVRARD, Yves; COLBERT, François. Arts Management: a new discipline entering the millennium? International Journal of Arts Management, vol. 2, n. 2, p. 4-13, 2000. Disponível em: <http://bit.ly/evrard2000>. Último acesso em: 8 jul. 2016.

FARIA, José Eduardo. Direito e globalização econômica: implicações e perspectivas. 2. ed. São Paulo: Malheiros, 1998.

FARTHING, Stephen. Tudo sobre arte. Trad. Paulo Polzonoff Jr. et al. Rio de Janeiro: Sextante, 2011.

FEATHER, John. From rights in copies to copyright: the recognition of authors'rights in English law and practice in the sixteenth and seventeenth centuries. In: JASZI, Peter; WOODMANSEE, Martha. (Org.). The Construction of Authorship: Textual Appropriation in Law and Literature. Dumhan e Londres: Duke University Press, 1994.

Publishing, Piracy and Politics: An Historical Study of Copyright in Britain. Londres: Mansell, 1994.

FELDMAN, Robin. Rethinking patent law. Harvard University Press, 2012.

FELTEN, Ed. The Pizzaright Principle. Freedom to Tinker. 28 set. 2005. Disponível em: $<$ http://bit.ly/felten2005>. Último acesso em: $15 \mathrm{dez} .2018$.

FIRTH, Alison. Signs, surfaces, shapes and structures - the protection of product design under trade mark law. In: DINWOODIE, Graeme.; JANIS, Mark. Trademark Law and Theory: A Handbook of Contemporary Research. Cheltenham: Edward Elgar, 2008.

FISHER, William W. An Alternative Compensation System. In: Promises to Keep: Technology, Law, and the Future of Entertainment. Stanford: Stanford University Press, 2004. Disponível em: <http://bit.ly/fisher2004>. Último acesso em: 15 dez. 2018.

. Theories of Intellectual Property. 2001. Disponível em: <http://bit.ly/fisher2001>. Último acesso em: 14 dez. 2018.

FISS, Owen M. The Death of the Law. Cornell Law Review, vol. 72, p. 1-16, nov. 1986. Disponível em: <http://bit.ly/fiss1986>. Último acesso em: 15 dez. 2018.

FLANAGAN, Andrew; HAMPP, Andrew. It's Official: Jay Z's Historic Tidal Launches With 16 Artist Stakeholders. Billboard. 30 mar. 2015. Disponível em: $<$ http://bit.ly/billboardtidal>. Último acesso em: 7 jul. 2016.

FOLEY, Steven. Buffering and the Reproduction Right: When is a Copy a Copy? Cybaris $^{T M}$, An Intellectual Property Law Review, vol. 1, n. 1, article 4, p. 99-123, 2010. Disponível em: <http://bit.ly/foley2010>. Último acesso em: 15 dez. 2018. 
FOUCAULT, Michel. O que é um autor? In: . Ditos e escritos: estética - literatura e pintura, música e cinema. Org. Manuel Barros da Motta. Trad. Inês Autran Dourado Barbosa. Rio de Janeiro: Forense Universitária, 2001. vol. III.

GALLOWAY, Susan; DUNLOP, Stewart. A critique of definitions of the cultural and creative industries in public policy. International Journal of Cultural Policy, vol. 13, n. 1, p. 17-31, 2007.

GALVEZ-BEHAR, Gabriel. Si loin, si proches. Inventeurs et artistes au regard de la propriété intellectuelle dans la France du XIXe siècle. Les mythes de la science: inventeurs et invention. Colóquio organizado por MSH - Nord-Pas-de-Calais, dez./2005, França. Disponível em: <http://bit.ly/galvez-behar>. Último acesso em: 14 dez. 2018 .

GAMA CERQUEIRA, João. Tratado da propriedade industrial. 2. ed. São Paulo: Revista dos Tribunais, 1982.

GANDELAMN, Henrique. De Gutenberg à internet: direito autorais na era digital. Rio de Janeiro: Record, 2001.

GARNIER, Joseph. Traité d'Économie Politique, sociale ou industrielle: exposé didactique des principes et des applications de cette science avec des développements sur le crédit, les banques, le libre échange, la protection, l'association, les salaires, etc. 7. ed. Paris: Garnier Frères et Guillaumin et $\mathrm{c}^{\mathrm{ie}}$, 1873. Disponível em: $<$ http://bit.ly/garnier1873>. Último acesso em: 13 dez. 2018.

GASTAMBIDE, Adrien. Traité théorique et pratique des contrefaçons en tous genres. Paris: Legrand et Descauriet, 1837. Disponível em: <http://bit.ly/gastambide1837>. Último acesso em: 13 dez. 2018.

GAUDRAT, Philippe. L'abus du droit moral. In: BRISON, Fabienne et al. (Org.). Moral Rights in the $21^{\text {st }}$ Century. Bruxelas: Larcier, 2015.

GAULTIER, Jean-François. Mémoire à consulter pour les libraires \& imprimeurs de Lyon, Rouen, Toulouse, Marseille \& Nismes concernant les privileges de librarie et continuations d'iceux. 1776. Disponível em: <http://goo.gl/D2C54H>. Último acesso em: 8 jul. 2016.

GAVIN, Gérard. Le droit moral de l'auteur dans la jurisprudence et la législation françaises. Paris: Dalloz, 1960.

GEIGER, Cristophe. Clef pour comprendre, améliorer et adherer: la fonction sociale des droits de propriété intellectuelle. In: VIVANT, Michel. Droit et économie de la propriété intellectuelle. Paris: LGDJ, 2014. 
GEORGE, Alexandra. Constructing Intellectual Property. Nova York: Cambridge University Press, 2012.

GERLINGS, Charlotte. 100 Great Artists: a visual journey from Fra Angelico to Andy Warhol. Londres: Arcturus, 2006.

GERVAIS, Daniel J. Quel avenir pour le droit moral? In: BRISON, Fabienne et al. (Org.). Moral Rights in the $21^{\text {st }}$ Century. Bruxelas: Larcier, 2015.

; JUDGE, Elizabeth F. Of Silos and Constellations: Comparing Notions of Originality in Copyright Law. Cardozo Arts \& Entertainment Law Journal, vol. 27, p. 375-408, 2009. Disponível em: <http://bit.ly/judge-gervais>. Último acesso em: 14 dez. 2018.

GHIDINI, Gustavo. Rethinking Intellectual Property: Balancing Conflicts of Interests in the Constitutional Paradigm. Cheltenham e Northampton: Edward Elgar, 2018.

GHOSH, Rishab A. Cooking pot markets: An economic model for the trade in free goods and services on the Internet. First Monday, vol. 3, n. 3, 2 mar. 1998. Disponível em: $<$ http://bit.ly/ghosh1998>. Último acesso em: $15 \mathrm{dez} .2018$.

GINSBURG, Jane C. A Tale of Two Copyrights: Literary Property in Revolutionary France and America. Tulane Law Review, vol. 64, n. 5, p. 993-1.031, maio 1990. Disponível em: <http://bit.ly/ginsburg1990>. Último acesso em: 10 dez. 2018.

. 'Courts Have Twisted Themselves into Knots' (and the Twisted Knots Remain to Untangle): US Copyright Protection for Applied Art after Star Athletica. In: DERCLAYE, Estelle (Org.). The Copyright/Design Interface: past, present and future. Nova York: Cambridge University Press, 2018.

Four Reasons and a Paradox: The Manifest Superiority of Copyright over Sui Generis Protection of Computer Software. Columbia Law Review, vol. 94, p. 2.5592.572, 1994. Disponível em: <http://bit.ly/ginsburg1994>. Último acesso em: 15 dez. 2018.

. Proto-property in literary and artistic works: sixteenth-century papal printing privileges. Columbia Public Law Research Paper, n. 14-478, 2015. Disponível em: $<$ http://ssrn.com/abstract=2650152>. Último acesso em: 10 jul. 2016.

. The Right to Claim Authorship in U.S. Copyright and Trademarks Law. Houston Law Review, vol. 41, n. 2, p. 263-307, 2004. Disponível em: $<$ http://bit.ly/ginsburg2004>. Último acesso em: 15 dez. 2018.

The Role of the Author in Copyright. In: OKEDIJI, Ruth L. (Org.). Copyright Law in an Age of Limitations and Exceptions. Nova York: Cambrige University Press, 2017. 
US initiatives to protect works of low authorship. In: DREYFUSS, Rochelle C; ZIMMERMAN, Diane L.; FIRST, Harry. Expanding boundaries of intellectual property: innovation policy for the knowledge society. Nova York: Oxford University Press, 2001.

GOLDSTEIN, Paul. Moral rights on the Internet. In: BRISON, Fabienne et al. (Org.). Moral Rights in the $21^{\text {st }}$ Century. Bruxelas: Larcier, 2015.

GOMBRICH, Ernst Hans Josef. A história da arte. 16. ed. rev., aum. e com novo projeto gráfico. Rio de Janeiro: LTC, 2000.

GOMPERTZ, Will. Isso é arte? 150 anos de arte moderna do impressionismo até hoje. Trad. Maria Luiza X. de A. Borges. Rio de Janeiro: Zahar, 2013.

GORDON, Wendy J. Asymmetric Market Potential And Prisoners' Dilemma: Two Simple Models with Significance for the Law of Copyright. University of Dayton Law Review, vol. 17, 1992. Disponível em: <http://bit.ly/gordon1992 $\geq$. Último acesso em: 15 de dezembro de 2018.

GOULD, Emily; HERMAN, Alexander. Copyright in Photographs of Paintings: The UK Approach, the Impact of European Jurisprudence and the Prospects in a Post-Brexit World. Art, Antiquity and Law, vol. XXII, n. 2, p. 159-171, jul. 2017.

GREFFE, Xavier. Arte e mercado. Org. Teixeira Coelho. Trad. Ana Goldberg. São Paulo: Iluminuras: Itaú Cultural, 2013.

GRIFFITHS, Jonathan. Moral rights from a copyright perspective. In: BRISON, Fabienne et al. (Org.). Moral Rights in the $21^{\text {st }}$ Century. Bruxelas: Larcier, 2015.

GROSHEIDE, Willem F. Globalisation, Convergence and Divergence in International Copyright Law. In: MACMILLAN, Fiona. (Org.). New Directions in Copyright Law. Londres: Edward Elgar, 2006. vol. 2.

GRZELAK, Victoria A. Key Mouse \& Sonny Bono Go to Court: The Copyright Term Extension Act and Its Effect On Current And Future Rights. John Marshall Review of Intellectual Property Law, vol. 2, p. 95-115, 2002. Disponível em: $<$ http://bit.ly/grzelak2002>. Último acesso em: $15 \mathrm{dez} .2018$.

GUIMARÃES, Aprigio Justiniano da Silva. Propriedade Litteraria: historico e sustentação d'um projecto a respeito, apresentado à camara dos senhores deputados em 14 de agosto de 1856. Recife: Typographia Academica, 1859.

HARDIN, Garrett. The tragedy of the commons. Science, new series, vol. 162, n. 3.859, p. 1.243-1.248, 1968. Disponível em: <http://bit.ly/hardin-1968>. Último acesso em: 15 dez. 2018. 
HAYEK, Friedrich August von. Individualism and Economic Order. Chicago: The University of Chicago Press, 1948.

. The Fatal Conceit: The Errors of Socialism. Chicago: The University of Chicago Press, 1988.

HEALD, Paul J. Losing to Disney: The Complex Lesson of Eldred v Ashcroft and the Corporate Control of Copyright. In: MACMILLAN, Fiona (Org.). New Directions in Copyright Law. Londres: Edward Elgar, 2006. vol. 2.

HEGEL, Georg Wilhelm Friedrich. Princípios da filosofia do direito. Trad. Orlando Vitorino. São Paulo: Martins Fontes, 1997.

HEIDEGGER. A origem da obra de arte. Trad. Idalina Azevedo e Manuel António de Castro. São Paulo: Edições 70, 2010.

HEINICH, Nathalie. Arts et sciences à l'âge classique. Actes de la Recherche en Sciences Sociales, vol. 66, n. 1, p. 47-78, 1987.

HELFER, Laurence R. The New Innovation Frontier? Intellectual Property and the European Court of Human Rights. Intellectual Property and Human Rights, vol. 49, n. 1, p. 1-52, 2008. Disponível em: <http://bit.ly/helfer2008>. Último acesso em: $15 \mathrm{dez}$. 2018.

HELL, François Joseph Antoine de. Rapport fait à l'Assemblée Nationale sur la propriété des productions scientifiques ou littéraires. Paris: Imprimerie Nationale, 1791. Disponível em: <http://goo.gl/MIHqXO>. Último acesso em: 8 jul. 2016.

HELLER Michael A. The tragedy of the anticommons: property in the transition from Marx to markets. Harvard Law Review, vol. 111, p. 621-688, 1968. Diponível em: $<$ http://bit.ly/heller1968>. Último acesso em: 15 dez. 2018.

HEN, Charles. La réimpression: étude sur cette question considérée principalement au point de vue des intérêts belges et français. Bruxelas: Auguste Decq, 1851.

HESS, Charlotte; OSTROM, Elinor. Introduction: An Overview of the Knowledge Commons. Understanding Knowledge as a Commons. Cambridge e Londres: MIT Press, 2007. Disponível em: <http://bit.ly/hess2007 >. Último acesso em: 15 dez. 2018.

HESSE, Carla. Enlightenment Epistemology and the Laws of Authorship in Revolutionary France, 1777-1793. Representations, n. 30, Special Issue: Law and the Order of Culture, p. 109-137, 1990. Disponível em: <http://bit.ly/hesse1990>. Último acesso em: 10 dez. 2018.

. The rise of intellectual property, 700 b.c.-a.d. 2000: an idea in the balance. Daedalus, p. 26-45, 2002. 
HETTINGER, Edwin C. Justifying Intellectual Property. Philosophy \& Public Affairs, vol. 18, n. 1, p. 31-52, 1989.

HETZEL, J. La propriété littéraire et le domaine public payant. 2. ed. Bruxelas: Imprimerie de Veuve J. Van Buggenhoudt, 1860. Disponível em: $<$ http://bit.ly/hetzel1858>. Último acesso em: 13 dez. 2018.

HEYMANN, Laura A. Overlapping intellectual property doctrines: election of rights versus selection of remedies. Stanford Technology Law Review, vol. 17, p. 241-247, 2013. Disponível em: <https://core.ac.uk/download/pdf/73972347.pdf>. Último acesso em: 14 dez. 2018.

. The Trademark/Copyright Divide. SMU Law Review, vol. 60, n. 1, artigo 3, p. 56102, 2007. Disponível em: <http://bit.ly/heymann2007>. Último acesso em: 16 dez. 2018.

HODGE, A. N. The History of Art: painting from Giotto to the present day. Londres: Arcturus, 2008.

HUARD, Adrien; MACK, Edouard. Répertoire de législation, de doctrine et de jurisprudence en matière de propriété littéraire et artistique. Paris: Marchal et Billard, 1891. Disponível em: <http://goo.gl/aMECIw>. Último acesso em: 8 jul. 2016.

HUARD, Gustave. Traité de la propriété intellectuelle: tome second - brevets d'invention, dessins et modèles industriels. Paris: Marchal et Billard, 1906.

HUGHES, Justin. The Philosophy of Intellectual Property. The Georgetown Law Journal, vol. 77, p. 287-366, 1988.

HUNTER, Dan; WOOD, Suzannah. The laws of design in the age of mechanical reproduction. Adelaide Law Review, vol. 37, 2016. Disponível em: $<$ http://bit.ly/hunter-wood>. Último acesso em: 15 dez. 2018.

HUYSSEN, Andreas. After the Great Divide: theories of representation and difference. Bloomington: Indiana University Press, 1987.

IHERING, Rudolf von. La dogmática jurídica. Buenos Aires: Editorial Losada, 1946.

JASZI, Peter. Is There Such a Thing as Post-Modern Copyright? In: BIAGIOLI, Mario; JASZI, Peter; WOODMANSEE, Martha (Org.). Making and Unmaking Intellectual Property: Creative Production in Legal and Cultural Perspective. Chicago e Londres: The University of Chicago Press, 2011.

. On the author effect: contemporary copyright and collective creativity. In: ; WOODMANSEE, Martha. (Org.). The Construction of Authorship: Textual 
Appropriation in Law and Literature. Dumhan e Londres: Duke University Press, 1994.

. Toward a Theory of Copyright: The Metamorphoses of Authorship. Duke Law Journal, p. 455-502, 1991.

; WOODMANSEE, Martha. Introduction. In: JASZI, Peter; WOODMANSEE, Martha (Org.). The Construction of Authorship: Textual Appropriation in Law and Literature. Dumhan e Londres: Duke University Press, 1994.

JOBARD, Jean-Baptiste-Ambroise-Marcellin. De la propriété de la pensée et de la contrefaçon considérée comme droit d'aubaine et de detraction. Versailles: Imprimerie de Marlin, 1837. Disponível em: <http://bit.ly/jobard1837>. Último acesso em: 13 dez. 2018.

JONES, Richard H. The Myth of the Idea/Expression Dichotomy in Copyright Law. Pace Law Review, vol. 10, rev. 551, n. 3, p. 551-607, 1990. Disponível em: $<$ http://bit.ly/jones1990>. Último acesso em: $13 \mathrm{dez} .2018$.

KAHN, Anne-Emanuelle. The Copyright/Design Interface in France. In: DERCLAYE, Estelle (Org.). The Copyright/Design Interface: past, present and future. Nova York: Cambridge University Press, 2018.

KANT, Immanuel. Élements métaphysiques de la doctrine du droit: première partie de la docrtine des moeurs - suivi d'un essai philosophique sur la paix perpétuelle et d'autres petits écrits relatfs au droit naturel. Trad. Jules Barni. Paris: Auguste Duran, 1853. Disponível em: <http://goo.gl/EUgtqu>. Último acesso em: 8 jul. 2016.

KATZ, Stanley N. The Oxford international encyclopedia of legal history. Oxford: Oxford, 2009. vol. 2.

. The Oxford international encyclopedia of legal history. Oxford: Oxford, 2009. vol. 3 .

KENNEDY, David. The International Human Rights Movement: Part of the Problem? European Human Rights Law Review, vol. 15, p. 101-126, 2002.

KINSELLA, Norman Stephan. Against Intellectual Property. Auburn: Ludwig von Mises Institute, 2015.

KITCH, Edmund W. K. Elementary and Persistant Errors in the Economic Analysis of Intellectual Property. Anderbilt Law Review, vol. 53, n. 6, p. 1.727-1.741, 2000.

KOSTYLO, Joanna. From gunpowder to Print: the Common origins of Copyright and Patent. In: BENTLY, Lionel; DEAZLEY, Ronan; KRETSCHMER, Martin (Org.). 
Privilege and Property: Essays on the History of Copyright. Cambridge: Open Book Publishers, 2010.

KRUEGER PELA, Juliana. Rembrant e o direito privado. Revista da Faculdade de Direito da Universidade de São Paulo, vol. 110, p. 319-327, jan.-dez. 2015. Disponível em: $<$ http://bit.ly/pela2015>. Último acesso em: $10 \mathrm{dez} .2018$.

KU, Raymond S. R. The Creative Descrution of Copyright: Napster and the New Economics of Digital Technology. The University of Chicago Law Review, vol. 69, n. 1, p. 263-324, 2009. Disponível em: <http://bit.ly/ku2009>. Último acesso em: 15 dez. 2018.

LABOULAYE, Édouard. Études sur la propriété littéraire en France et en Angleterre. Paris: Auguste Duran, 1858. Disponível em: <http://bit.ly/laboulaye1858>. Último acesso em: 13 dez. 2018.

LADAS, Stephen P. The international protection of literary and artistic property. Nova York: Macmillan, 1938. vol. I.

LADDIE, Hugh; PRESCOTT, Peter; VITORIA, Mary. The modern law of copryight and designs. 2. ed. Londres: Butterworths, 1995.

LAHORGUE NUNES, Simone. Brazil. In: THORNE, Clive. International Design Protection: A Global Handbook. Londres: Globe Business Publishing, 2012.

. Direito autoral e direito antitruste. Rio de Janeiro: Elsevier, 2011.

LAKANAL, Joseph. Exposé sommaire des travaux de Joseph Lakanal, ex-membre de la Convention Nationale et $d u$ Conseil des Cinq-Cents: Pour sauver, durante la révolution, les sciences, les lettres, et ceux qui les honoroient par leurs travaux. Paris: Typographie de Firmin Didot Frères, 1838. Disponível em: <http://bit.ly/lakanal1838>. Último acesso em: 13 dez. 2018.

LANDAU, Michael. Dastar v. Twentieth Century Fox: The Need For Stronger Protection of Attribution Rights in The United States. NYU Annual Survey of American Law, vol. 61, p. 273-316, 2005.

LANDES, William. M.; POSNER, Richard. A. An Economic Analysis of Copyright Law. The Journal of Legal Studies, vol. 18, n. 2, p. 325-363, jun. 1989. Disponível em: $<$ http://bit.ly/landes-posner>. Último acesso em: 14 dez. 2018.

. Indefinitely Renewable Copyright. University of Chicago Law Review, vol. 70, n. 2, p. 471-518, 2003. Disponível em: < http://bit.ly/landes-posner2003>. Último acesso em: 15 dez. 2018. 
LANG, Brent. Disney Outlines Streaming Service, Will Launch in Late 2019. Variety. 7 ago. 2018. Disponível em: <http://bit.ly/variety2017d>. Último acesso em: 15 dez. 2018.

LAVIK, Erlend. Romantic authorship in copyright law and the uses of aesthetics. In: EECHOUD, Mireille van (Org.). The Work of Authorship. Amsterdã: The Amsterdam University Press, 2014.

LAVOLLÉ, R. Les traités de commerce et les conventions littéraires. Paris: Cercle de la librairie..., 1891. Disponível em: <http://goo.gl/AoJ0LJ>. Último acesso em: 8 jul. 2016.

LE CHAPELIER, Isaac. Rapport fait par M. Le Chapelier, au nom du Comité de Constitution, sur la pétition des auteurs dramaiques, dans la séance du jeudi 13 janvier 1791, avec de décret rendu dans cette séance. Paris: L’Imprimerie Nationale, 1791. Disponível em: <http://goo.gl/dARYW7>. Último acesso em: 8 jul. 2016.

LEMLEY, Mark A. Book Review: Romantic Authorship and the Rhetoric of Property. Texas Law Review, vol. 75, 1997.

LEMOS, Ronaldo. Creative commons, mídia e as transformações recentes do direito da propriedade intellectual. Revista Direito GV, vol. 1, n. 1, p. 181-187, maio 2005. Disponível em: <http://bit.ly/lemos2005a > Último acesso em: 15 dez. 2018.

. Direito, tecnologia e cultura. 2. ed. Rio de Janeiro: Ed. FGV, 2005. Disponível em: < http://bit.ly/lemos2005b>. Último acesso em: 15 dez. 2018.

. From Legal Commons to Social Commons: Brazil and the Cultural Industry in the $21^{\text {st }}$ Century. Working Paper CBS 80-07, University of Oxford Centre for Brazilian Studies. Disponível em: < http://bit.ly/lemos2009>. Último acesso em: 15 dez. 2018.

LEONARDI, Fernanda Stinchi Pascale. Licenças compulsórias e direitos autorais. 2014. Tese (Doutorado). Orientadora: Professora Titular Silmara Juny de Abreu Chinellato Faculdade de Direito da Universidade de São Paulo, São Paulo.

LESSIG, Lawrence. Cultura livre: como a mídia usa a tecnologia e a lei para barrar a criaçã cutlural e controlar a criatividade. Trad. Fábio Emilio Costa. 2004. Disponível em: < http://bit.ly/lessig2004>. Último acesso em: 15 dez. 2018.

. The Future of Ideas: the fate of the commons in a connected world. Nova York: Random House, 2001. Disponível em: <http://bit.ly/lessig2001>. Último acesso em: 15 dez. 2018.

LEVINE, David K. et al. Competition and Innovation. Cato Papers on Public Policy, vol. 1, p. 2-62, 2011. Disponível em: <http://bit.ly/levineetal>. Último acesso em: $15 \mathrm{dez}$. 2018. 
LIEBOWITZ, Stan J. Alternative Copyright Systems: The Problems with a Compulsory License. 2003. Disponível em: <http://bit.ly/liebowitz2003>. Último acesso em: 15 dez. 2018.

LIMA LOPES, José Reinaldo. O Oráculo de Delfos: O Conselho de Estado no Brasilimpério. São Paulo: Saraiva, 2010.

LINGUET, Simon-Nicolas-Henri. Annales politiques, civiles, et littéraires du XVIIIe siècle. Londres, 1777. vol. III. Disponível em: <http://bit.ly/linguet1777>. Disponível em: 13 dez. 2018.

LITMAN, Jessica D. The Public Domain. Emory Law Journal, vol. 39, n. 4, p. 965-1.023, 1990.

LOCKE, John. Memorandum on the 1662 Licensing Act. In: KING, Lord. The life of John Locke: with extracts from his correspondence, journals, and common-place books. Londres: Henry Colburn and Richard Bentley, 1830. vol. 1. Disponível em: $<$ http://bit.ly/locke1964>. Último acesso em: 10 dez. 2018.

LOCRÉ, Baron. Discussions sur la liberté de la presse, la censure, la propriété littéraire, l'imprimerie et la libraire qui ont eu lieu dans le Conseil d'État, pendant les années 1808, 1809, 1810 et 1811. Paris: Garnery et Nicolle, 1819. Disponível em: $<$ http://goo.gl/UjGwUq>. Último acesso em: 8 jul. 2016.

LOVE, James. Artists want to be paid: the blur/baff proposal. Blur $02 \mid$ Power at Play in Digital Art and Culture, 11-13 abr. 2003. Disponível em: <http://bit.ly/love2003>. Último acesso em: 15 dez. 2018.

LUCAS-SCHLOETTER, Agnès. Rapport général: le droit moral dans les différents régimes du droit d'auteur. In: BRISON, Fabienne et al. (Org.). Moral Rights in the $21^{\text {st }}$ Century. Bruxelas: Larcier, 2015.

MACHLUP, Fritz. An Economic Review of the Patent System: Study of the Subcommittee on Patents, Trademarks, and Copyrights of the Committee on the Judiciary United States - Study $n^{\circ} 15$. Washington: Government Printing Office, 1958. Disponível em: $<$ http://bit.ly/machlup1958>. Último acesso em: 15 dez. 2018.

MAMARBACH, R.; DAY, M.; FAVATO, G. Evaluating art as an alternative investment asset. The capco institute journal of financial transformation, p. 63-71, 2008.

MANDEVILLE, Bernard. The Fable of the Bees: or private vices, public benefits. Comentários: F.B. Kaye. Indianápolis: Liberty Fund, 2008.

MANN, Ronald J. Comment - Patents in the software industry. In: DREYFUSS, Rochelle C.; ZIMMERMAN, Diane L.; FIRST, Harry. Expanding boundaries of intellectual 
property: innovation policy for the knowledge society. Nova York: Oxford University Press, 2001.

MARTINO, Agnaldo; SAPATERRA, Ana Paula. A censura no Brasil do século XVI ao século XIX. Estudos Lingüísticos, vol. 15, p. 234-243, 2006. Disponível em: $<$ http://bit.ly/martino-sapaterra>. Último acesso em: 22 dez. 2018.

MARTINS, Samuel. Direito autoral: seu conceito, sua história e sua legislação entre nós. Recife: Officinas da Livraria Franceza, 1906.

MARTINS, Wilson. A palavra escrita: história do livro, da imprensa, e da biblioteca. São Paulo: Anhembi, 1957.

MASIYAKURIMA, Patrick. The Trouble with Moral Rights. Modern Law Review, vol. 68, n. 3, p. 411-434, 2005.

MAUGRAS, Émile; GUÉGAN, Maurice. Le Cinématrographe devant le droit. Paris: V. Giard \& E. Brière, 1908.

MAZZUCATO, Mariana. The entrepreneurial state: debunking public vs. private sector myths. Londres e Nova York: Anthem Press, 2013.

MÉMOIRE Présenté à l'Assemblée Nationale au Nom des Imprimeurs-Libraires, Propriétaires des Priviléges des diverses Liturgies de France. 1790. Disponível em: $<$ http://biblioteca.versila.com/21771902>. Último acesso em: 8 jul. 2016.

MÉMOIRE sur la contestation qui est entre les libraires de paris et ceux de Lyon au sujet des priviléges et des continuations que le Roy accord pour l'impression des livres. 1690. Disponível em: <http://goo.gl/nZVHt0>. Último acesso em: 8 jul. 2016.

MENEGATTI, André Luís. Em Busca da Biblioteca Digital de Alexandria: pensando a partir do caso Google Books e da gestão coletiva de direitos autorais. São Paulo: Lumen Juris, 2017.

MERGES, Robert P. Are you making fun of me?: notes on market failure and the parody defense in copyright. AIPLA Q.J., vol. 21, p. 305-312, 1993.

. Justifying Intellectual Property. Cambridge e Londres: Harvard University Press, 2011. Disponível em: <http://bit.ly/merges1993>. Último acesso em: 15 dez. 2018.

MIGUEZ, Paulo. Alguns aspectos do processo de constituição do campo de estudos em economia da cultura. IV ENECULT - Encontro de Estudos Multidisciplinares em Cultura 28 a 30 de maio de 2008. Faculdade de Comunicação/UFBa, Salvador-BahiaBrasil. 
MILHAUPT, Curtis J.; PISTOR, Katharina. Law and Capitalism: what corporate crises reveal about legal systems and economic development around the world. Columbia Law and Economics Working Paper, n. 313, 2008.

MILTON, John. Eikonoklastes: in Answer To a Book Intitl'd Eikon Basilike, The Portrature of his Sacred Majesty in his Solitudes and Sufferings. Londres: Matthew Simmons, 1649. Disponível em: <http://bit.ly/2eikonoklastes1649>. Último acesso em: 15 dez. 2018.

MISQUITTA, Anthony. What is Art? Artistic Craftsmanship Revisited. Art, Antiquity and Law, vol. XIV, n. 3, p. 282-290, oct. 2009.

MONTALEMBERT, Charles Forbes René de. Oeuvres de M. le Comte de Montalembert: l'un des quarante de l'Académie Française. Paris: Jacques Lecoffre et C $C^{\text {ie }}, 1860$. vol. 1. Disponível em: <http://bit.ly/montalembert1848>. Último acesso em: 14 dez. 2018.

MORILLOT, André. De la nature du droit d'auteur. Revue critique de législation et de jurisprudence, XXVII ${ }^{\mathrm{e}}$ année, nouvelle série, tome VII, 1878. Disponível em: $<$ http://goo.gl/OPlKYr>. Último acesso em: 8 jul. 2016.

. De la personnalité du droit de publication qui appartient à un auteur vivant. 1872. Disponível em: <http://goo.gl/xxFKhI>. Último acesso em: 8 jul. 2016.

MORO, Maitê Cecília Fabbri. Marcas tridimensionais: sua proteção e os aparentes conflitos com a proteção outorgada por outros institutos da propriedade intelectual. São Paulo: Saraiva, 2009.

MOUCHET, Carlos; RADAELLI, Sigfrido A. Derechos intelectuales sobre las obras literárias y artísticas. Buenos Aires: Guillermo Kraft, 1948. t. I.

MOULIN, Raymonde. Le marché et le musée. La constitution des valeurs artistiques contemporaines. Revue française de sociologie, 27-3, Sociologie de l'art et de la literature, p. 369-395, 1986.

MURPHY, Richard. Theorizing the Avant-Garde: modernism, expressionism, and the problem of post-modernism. Cambridge: Cambridge University Press, 1998.

MUSKER, David. The Overlap between Patent and Design Protection. In: WILKOF, Neil; BASHEER, Shamnad (Org.). Overlapping Intellectual Property Rights. Oxford: Oxford University Press, 2012.

NADEL, Mark S. Questioning the economic justification for copyright. 2003. Disponível em: <http://bit.ly/nadel2003>. Último acesso em: 15 dez. 2018.

NAPOLITANO, Carlos José. A regulação da propriedade imaterial na Constituinte de 87/88: direito à comunicação, direitos fundamentais e econômicos Revista de 
Informação Legislativa, Brasília, ano 48, n. 189, jan.-mar. 2011. Disponível em: $<$ http://bit.ly/napolitano2011>. Último acesso em: 14 dez. 2018.

NAZARENO, Cláudia. O "atual" direito autoral, as trocas peer-to-peer de músicas e vídeos pela internet e os projetos de lei que tratam dos crimes cibernéticos. Brasília: Câmara dos Deputados, 2009. Disponível em: <http://bit.ly/nazareno2009>. Último acesso em: 15 dez. 2018.

O software, a legislação brasileira proposições em andamento na Câmara. Brasília: Câmara dos Deputados, 2004. Disponível em: <http://bit.ly/nazareno2004>. Último acesso em: 15 dez. 2018.

NETANEL, Ney W. Impose a noncommercial use levy to allow free peer-to-peer file sharing. Harvard Journal of Law \& Technology, vol. 17, n. 1, 2003. Disponível em: $<$ http://bit.ly/netanel2010>. Último acesso em: 15 dez. 2018.

. Why Has Copyright Expanded? Analysis and Critique. In: MACMILLAN, Fiona. (Org.). New Directions in Copyright Law. Cheltenham e Northampton: Edward Elgar, 2007. vol. 6 .

OSTROM, Elinor. Beyond Markets and States: Polycentric Governance of Complex Economic Systems. The American Economic Review, vol. 100, n. 3, p. 641-672, jun. 2010. Disponível em: <http://bit.ly/ostrom2010>. Último acesso em: 15 dez. 2018.

; OSTROM, Vincent. Public goods and public choices. In: SAVAS, E. S. (Org.). Alternatives for delivering public services: towards improved performance. Boulder: Westview Press, 1977.

PASTOR, Javier. Disney compra la mayor parte Fox por 52.400 millones de dólares y prepara su imperio televisivo. Xataka. 14 dez. 2017. Disponível em: $<$ http://bit.ly/xataka2017>. Último acesso em: 15 dez. 2018.

PATAILLE, J. Annales de la propriété industrielle artistique et littéraire. Journal de législation, docrtine et jurisprudence françaises et étrangères..., tomo XVI, 1870. Paris. Disponível em: <http://goo.gl/02Fw2f>. Último acesso em: 8 jul. 2016.

PATTERSON, Lyman Ray. Copyright in Historical Perspective. Nashville: Vanderbilt University Press, 1968.

PAUL, Joanna. The "Piracy Paradox" Is So Last Year: Why the Design Piracy Prohibition Act is the New Black. Disponível em: <http://bit.ly/paul2009>. Último acesso em: 15 dez. 2018.

PEDROSO, Antonio de Sousa. Tratado de propriedade literária e artística: direito interno, comparado e internacional. Porto: Renascença Portuguesa, 1918. 
PICARD, Edmond. Embryologie juridique: nouvelle classification des droits. Journal du Droit International Privé, t. 10, n. XI-XII, p. 565-585, 1881.

PIKETTY, Thomas. O capital no século XXI. Trad. Monica Baumgarten de Bolle. Rio de Janeiro: Intrínseca, 2014.

PINHEIRO, Ivan Nogueira. A evolução histórica dos direitos de autor: da invenção da imprensa a sua positivação. 2008. Dissertação (Mestrado). Orientador: Prof. Doutor Ignácio Maria Poveda Velasco - Faculdade de Direito da Universidade de São Paulo, São Paulo.

PINHO, Diva Benevides. A arte como investimento: a dimensão econômica da cultura. São Paulo: Nobel - EDUSP, 1989.

PLUQUET, François-André-Adrien. Troisième lettre à un ami, concernant les affaires de la librarie. 1778. Disponível em: <http://goo.gl/wP7ot2>. Último acesso em: 8 jul. 2016.

POLANVYI, Micahel. Patent Reform. The Review of Economic Studies, vol. 11, n. 2, p. 61-76, 1994. Disponível em: <http://bit.ly/polanvyi>. Último acesso em: 15 dez. 2018.

PORTUGAL GOUVÊA, Carlos Pagano Botana. Social Rights Against the Poor. Vienna Journal on International Constitutional Law, vol. 7, n. 4, p. 454-475, 2013. Disponível em: <http://bit.ly/pgouvea2013>. Último acesso em: 15 dez. 2018.

QUEMIN, Alain. International contemporary art fairs in a 'globalized' art market. European Societies, vol. 15, n. 2, p. 162-177, 2013. Disponível em: $<$ http://bit.ly/quemin2013>. Último acesso em: 15 dez. 2018.

RAHMATIAN, Andreas. Copyright and Creativity: the making of property rights in creative works. Cheltenham e Northampton: Edward Elgar, 2011.

RAJAN, Mira T. Sundara. The attribution right: authorship and beyond. In: BRISON, Fabienne et al. (Org.). Moral Rights in the $21^{\text {st }}$ Century. Bruxelas: Larcier, 2015.

RAMELLO, Giovanni B. Private appropriability and sharing of knowledge: convergence or contradiction? The opposite tragedy of the creative commons. In: GORDON, Wendy J.; TAKEYAMA, Lisa N.; TOWSE, Ruth (Org.). Developments in the economics of copyright: research and analysis. Cheltenham: Edward Elgar, 2005.

RAUSTIALA, Kal; SPRINGMAN, Cristopher. The Piracy Paradox: Innovation and Intellectual Property in Fashion Design. Virginia Law Review, vol. 92, n. 8, p. 1.6871.777, dec. 2006. Disponível em: <http://bit.ly/raustiala>. Último acesso em: $15 \mathrm{dez}$. 2018. 
REASONS for objecting to the renewal of the Licensing Act. Londres, 1695. Disponível em: <http://goo.gl/P7A1I9>. Último acesso em: 10 jun. 2016.

REDMOND-COOPER, Ruth. Moral Rights. Diploma in Art Law. Module 2 - Artists' Rights. Institute of Art and Law. 2016[?].

REICHMAN, Jerome H. Charting the colapse of the patent-copyright dichotomy: premises for a restructured international intellectual property system. Cardozo Arts \& Entertainment Law Journal, vol. 13, p. 475-520, 1995. Disponível em: $<$ http://bit.ly/reichman1995>. Último acesso em: 10 dez. 2018.

. Legal hybrids between the patent and copyright paradigms. Columbia Law Review, vol. 94, p. 2.432-2.558, 1994. Disponível em: <http://bit.ly/reichman1994>. Último acesso em: 10 dez. 2018.

REIS, Ana Carolina Fonseca. Marketing cultural e financiamento da cultura: teoria e prática em estudo internacional comparado. São Paulo: Pioneira Thomson Learning, 2003.

REMÉDIO MARQUES, João Paulo. Propriedade intelectual e interesse público. Boletim da Faculdade de Direito da Universidade de Coimbra, vol. 79, p. 293-354, 2003.

REPUBLICA dos Estados Unidos do Brasil. Annaes da Assembleia Nacional Constituinte: organizados pela redação dos annaes e documentos parlamentares. Rio de Janeiro: Imprensa Nacional, 1936. vol. X. Disponível em: <http://bit.ly/anais1936t10>. Último acesso em: 14 dez. 2018.

REPÚBLICA dos Estados Unidos do Brasil. Anais da Assembléia Constituinte: organizados pela redação dos anais e documentos parlamentares. Rio de Janeiro: Departamento de Imprensa Nacional, 1946. vol. I. Disponível em: $<$ http://bit.ly/anais1946>. Último acesso em: 14 dez. 2018.

RICKETSON, Sam; SUTHERSANEN, Uma. The Design/Copyright Overlap: Is there a Resolution? 2012. Disponível em: <http://bit.ly/ricketson-suthersanen>. Último acesso em: 14 dez. 2018.

RIGAMONTI, Cyrill P. Deconstructing Moral Rights. Harvard International Law Journal, vol. 47, n. 2, p. 353-412, 2006.

RISS, Thomas. Functional and Economic Criteria as a Base for Systematization of IP Law. In: IPR UNIVERSITY CENTER. In Search of New IP Regimes. Helsinki: Oy Nord Print Ab, 2010.

RIVAROZA, Enrique E. Propriedade literaria en la legislación y en la doctrina. Buenos Aires: Tipografia de los Estudiantes, 1887. 
ROSATTI, Eleonora. The idea/expression dichotomy: friend or foe? In: WATT, Richard (Org.). Handbook on the Economics of Copyright: A Guide for Students and Teachers. Cheltenham e Northampton: Edward Elgar, 2014.

ROSE, Mark. The Author as Proprietor: Donaldson v. Becket and the Genealogy of Modern Authorship. Representations, n. 23, p. 51-85, 1988. Disponível em: $<$ http://bit.ly/rose1988>. Último acesso em: $10 \mathrm{dez} .2018$.

The Author in Court: Pope v. Curll (1741). In: JASZI, Peter; WOODMANSEE, Martha (Org.). The Construction of Authorship: Textual Appropriation in Law and Literature. Dumhan e Londres: Duke University Press, 1994.

ROSENMEIER, Morten. Introduction: droit moral in the past and in the future. Some short reflections. In: BRISON, Fabienne et al. (Org.). Moral Rights in the $21^{\text {st }}$ Century. Bruxelas: Larcier, 2015.

RUIJSENAARS, H. Protecting the integrity of broadcast signals. In: BRISON, Fabienne et al. (Org.). Moral Rights in the $21^{\text {st }}$ Century. Bruxelas: Larcier, 2015.

SÁDABA, Igor. Propriedad intelectual: ¿bienes públicos o mercancías privadas? Madrid: Catarata, 2008.

SALOMÃO FILHO, Calixto. Novo estruturalismo jurídico: uma alternativa para o direito? Revista dos Tribunais, vol. 926 (edição comemorativa de 100 anos), ano 101, dez. 2012.

Teoria crítico-estruturalista do direito comercial. São Paulo: Marcial Pons, 2015.

; FERRÃO, Brisa Lopes de Mello; RIBEIRO, Ivan César. Concentração, estruturas e desigualdade: as origens coloniais da pobreza e da má distribuição de renda. São Paulo: Idcid, 2006.

SAMUELSON, Pamela. Should economics play a role in copyright law and policy? In: GORDON, Wendy J.; TAKEYAMA, Lisa N.; TOWSE, Ruth. Developments in the economics of copyright: research and analysis. Cheltenham: Edward Elgar, 2005.

et al. Manifesto concerning the legal protection of computer programs. Columbia Law Review, vol. 94, p. 2.308-2.431, 1994. Disponível em: $<$ http://bit.ly/samuelson1994>. Último acesso em: 15 dez. 2018.

SANTAELLA, Lúcia. Matrizes da linguagem e pensamento. São Paulo: Iluminuras, 2009.

SANTANA, Daniela Cristina Alves. As criações de moda e o direito de autor. 2007. Dissertação (Mestrado). Orientadora: Professora Doutora Silmara Juny de Abreu Chinellato de Almeida - Faculdade de Direito da Universidade de São Paulo, São Paulo. 
SAUNDERS, David. Authorship and Copyright. Londres e Nova York: Routledge, 1992.

. Dropping the Subject: An Argument for a Positive History of Authorship and the Law of Copyright. In: SHERMAN, Brad; STROWEL, Alain. (Org.). Of Authors and Origins: Essays on copyright law. Oxford: Clarendon Press: 1994.

SCHAUMANN, Niels B. Copyright Infringement and Peer-to-Peer Technology. William Mitchell Law Review, vol. 28, n. 3, art. 13, 2002. Disponível em: $<$ http://bit.ly/schaumman2002>. Último acesso em: 15 dez. 2018.

SCHULTE-SASSE, Jochen. Prefácio. In: BÜRGER, Peter. Theory of the avant-garde. Trad. Suhrkamp Verlag. Manchester: Manchester University Press, 1984.

SCHUMPETER, Joseph A. Capitalism, Socialism and Democracy. Londres: Routledge, 1994.

SCOTCHMER, Suzanne. Standing on the Shoulders of Giants: Cumulative Research and the Patent Law. Journal of Economic Perspectiver, vol. 5, n. 1, p. 29-41, 1991. Disponível em: <http://bit.ly/scotchmer1991>. Último acesso em: 15 dez. 2018.

SGANGA, Caterina. Propertizing European Copyright: History, Challenges and Opportunities. Cheltenham e Northampton: Edward Elgar, 2018.

SHAVELL, Steven; VAN YPERSELE, Tanguy. Rewards versus intellectual property rights. The Journal of Law and Economics, vol. 44, p. 525-547, 2001. Disponível em: $<$ http://bit.ly/shavell2001>. Último acesso em: 15 dez. 2018.

SHAVER, Lea. Access to knowledge in Brazil: new research on intellectual property, innovation and development. New Haven: Information Society Project, 2008.

SICCA, Gerson dos Santos. A Proteção da propriedade intelectual dos programas de computador. Revista de Informação Legislativa, Brasília, vol. 36, n. 142, p. 9-16, abr.jun. 1999. Disponível em: <http://bit.ly/sicca99>. Último acesso em: 15 dez. 2018.

SIEYÈS, Emmanuel-Joseph. Séance du 20 janvier. In: BUCHEZ, B. J.; ROUX, P. (Org.). Histoire parlementaire de la Révolution Française. 1834. vol. 4. Disponível em: $<$ http://bit.ly/sieyes1790>. Último acesso em: 10 dez. 2018.

SILVA, José Afonso da. Curso de direito constitucional positivo. 19. ed. São Paulo: Malheiros, 2001.

SILVEIRA, Newton. Direito de autor no design. 2. ed. São Paulo: Revista dos Tribunais, 2012.

Propriedade intelectual: propriedade industrial, direito de autor, software, cultivares, nome empresarial. 4. ed. São Paulo: Manole, 2011. 
SIRINELLI, Pierre. Rapport général. In: BRISON, Fabienne et al. (Org.). Moral Rights in the $21^{\text {st }}$ Century. Bruxelas: Larcier, 2015.

SMIERS, Joost. Is copyright fit for the $21^{\text {st }}$ century? No! In: GROSHEIDE, Willem (Org.). Intellectual Property and Human Rights: A Paradox. Cheltenham e Northahmpton: Edward Elgar, 2015.

SMITH, Adam. The Theory of Moral Sentiments. Nova York: Prometheus Books, Amherst, 2000.

STOKES, Simon. Copyright in Commissioned Paintings. Art, Antiquity and Law, vol. 5, n. 1, p. 77-79, mar. 2000.

STRÖMHOLM, Stig. Le droit moral de l'auteur en droit allemand, français et scandinave avec un aperçu de l'évolution international: étude de droit comparé. Stockholm: P.A. Norstedt \& Söners Förlag, 1966.

SUTHERSANEN, Uma. Copyright Law: a Stakeholders' Palimpsest. In: MACMILLAN, Fiona (Org.). New Directions in Copyright Law. Cheltenham: Edward Elgar, 2007. vol. 5.

Creative Commons: the other way? Learned Publishing, vol. 20, n. 1, p. 59-68, jan. 2007.

TEILMANN, Stina. Justifiations for Copyright: The Evolution of le droit moral. In: MACMILLAN, Fiona (Org.). New Directions in Copyright Law. Cheltenham e Northampton: Edward Elgar, 2005. vol. 1.

TEPPER, Steven Jay. Creative Assets and the Changing Economy. Journal of Arts Management, Law and Society, vol. 2, n. 2, p. 159-168, 2002. Disponível em: $<$ http://bit.ly/tepper2002>. Último acesso em: 8 jul. 2016.

THOMAS, Jean. Convention littéraire \& artistique internationale signée à Berne le 9 septembre 1886. [Paris?]: Bone, 1894. Disponível em: <http://goo.gl/hIJDhx >. Último acesso em: 8 jul. 2016.

THORTON, Sarah. Siete días en el mundo del arte. Trad. Laura Witner. 2. reimpr. Buenos Aires: Edhasa, 2010.

TORREMANS, Paul L. C. Introduction. In: BRISON, Fabienne et al. (Org.). Moral Rights in the $21^{\text {st }}$ Century. Bruxelas: Larcier, 2015.

. Moral Rights in the Digital Age. In: STAMATOUDI, Irini A.; TORREMANS, Paul L. C. (Org.). Copyright in the New Digital Environment: The Need to Redesign Copyright. Londres: Sweet \& Maxwell, 2000. 
TOWSE, Ruth. Cultural Economics, Copyright and Cultural Industries. Society and Economy in Central and Eastern Europe, vol. 22, n. 4, p. 107-134, 2000. Disponível em: < http://bit.ly/towsen2000>. Último acesso em: 14 fev. 2016.

TRIGO, Luciano. A grande feira: uma reação ao vale-tudo na arte contemporânea. Rio de Janeiro: Civilização Brasileira, 2009.

UNCTAD. Summary - Creative Economy Report 2008: The challenge of assessing the creative economy: towards informed policy-making, 2008. Disponível em: $<$ http://bit.ly/unctad2008a>. Último acesso em: 15 dez. 2018.

UNGER, Roberto Mangabeira. What should legal analysis become? New York: Verso, 1996.

VAREJÃO, Adriana. Povo de cores infinitas. São Paulo[?]: 2014. ARTE!Brasileiros, 24 mar. 2014. Disponível em: <http://brasileiros.com.br/uY6sQ>. Último acesso em: 15 fev. 2016.

VEBLEN, Thorstein. The Theory of the Leisure Class. Nova York: Oxford University Press, 2007.

VEIGA, Roberto de Magalhães. Mercado de arte: novas e velhas questões. In: BOLAÑO, César et al. (Org.). Economia da arte e da cultura. São Paulo: Itaú Cultural, 2010.

VELHO, Diogo. Direito de autor: projecto apresentado ao Senado. Rio de Janeiro: Villeneuve, 1886.

VENOSA, Sílvio de Salvo. Direito civil: parte geral. 14. ed. São Paulo: Atlas, 2014. vol. 1.

VIRGIL, Johnny. A biblioteca de Babel: uma metáfora para a sociedade da informação. DataGramaZero, vol. 8, n. 4, ago. 2007. Disponível em: <http://bit.ly/virgil2007>. Último acesso em: 15 dez. 2018.

WARBURTON, William. Letter from an author concerning literary property. In: HURD, R. (Org.). The Works of the Right Reverend William Warburton. Londres: Cadell \& Davies, 1811. vol. 12. Disponível em: <http://bit.ly/warburton1747>. Último acesso em: 10 dez. 2018.

WARHOL, Andy. The Philosophy of Andy Warhol: from A to B and back again. Londres: Penguin, 2007.

WERRA, Jacques de. Moral rights, a view from continental Europe. In: BRISON, Fabienne et al. (Org.). Moral Rights in the $21^{\text {st }}$ Century. Bruxelas: Larcier, 2015.

WESTKAMP, Guido. Convergence of IPRs and the establishment of hibrid protections under TRIPs. In: MACMILLAN, Fiona. (Org.). New Directions in Copyright Law. Cheltenham e Northampton: Edward Elgar, 2005. vol. 1. 
. TRIPS Principles, Reciprocity and the Creation of Sui-Generis-Type Intellectual Property Rights for New Forms of Technology. The Journal of World Intellectual Property, vol. 6, n. 6, p. 827-859, 2003. Disponível em: <http://bit.ly/westkamp2003>. Último acesso em: 15 dez. 2018.

WILBANKS, John; BOYLE, James. Introduction to Science Commons. 3 ago. 2006. Disponível em: <http://bit.ly/wilbanks2006>. Último acesso em: 15 dez. 2018.

WOODMANSEE, Martha. The Genius and the Copyright: economic and legal conditions of the emergence of the 'author'. Eighteenth-Century Studies, vol. 17, n. 4, Special Issue: The Printed Word in the Eighteenth Century, p. 425-448, 1984. Disponível em: $<$ http://bit.ly/wood1984>. Último acesso em: 10 dez. 2018.

WRIGHT, Brian D. The Economics of Invention Incentives: Patents, Prizes, and Research Contracts. The American Economic Review, vol. 73, n. 4, p. 691-707, sep. 1983. Disponível em: <http://bit.ly/wright1983>. Último acesso em: 15 dez. 2018.

XIFARAS, Mikhaïl. Le copyleft et la théorie de la propriété. Multitudes, vol. 41, p. 50-64, 2010. Disponível em: <http://bit.ly/xifaras2010>. Último aceso em: 15 dez. 2018.

YOUNG, Edward. Conjectures on Original Composition. Manchester: Longmans, Green \& Co, 1918. Disponível em: <http://bit.ly/young18>. Último aceso em: 16 dez. 2018.

ZILBERMAN, Regina. A literatura no marco da economia da cultura. In: BOLAÑO, César et al. (Org.). Economia da arte e da cultura. São Paulo: Itaú Cultural, 2010. 